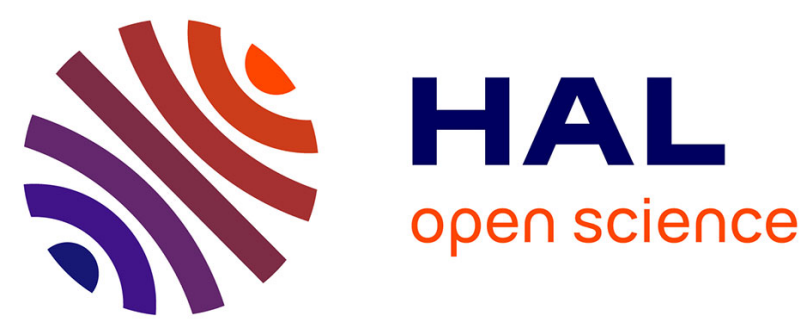

\title{
Squeal analysis based on the laboratory experimental bench "Friction-Induced Vibration and noisE at École Centrale de Lyon" (FIVE@ECL)
}

\author{
Jean-Jacques Sinou, D Lenoir, S Besset, Frédéric Gillot
}

\section{To cite this version:}

Jean-Jacques Sinou, D Lenoir, S Besset, Frédéric Gillot. Squeal analysis based on the laboratory experimental bench "Friction-Induced Vibration and noisE at École Centrale de Lyon" (FIVE@ECL). Mechanical Systems and Signal Processing, 2019, 119, pp.561 - 588. 10.1016/j.ymssp.2018.07.006 . hal-03256083

\section{HAL Id: hal-03256083 \\ https://hal.science/hal-03256083}

Submitted on 10 Jun 2021

HAL is a multi-disciplinary open access archive for the deposit and dissemination of scientific research documents, whether they are published or not. The documents may come from teaching and research institutions in France or abroad, or from public or private research centers.
L'archive ouverte pluridisciplinaire HAL, est destinée au dépôt et à la diffusion de documents scientifiques de niveau recherche, publiés ou non, émanant des établissements d'enseignement et de recherche français ou étrangers, des laboratoires publics ou privés. 
J-J. Sinou, D. Lenoir, S. Besset and F. Gillot, Squeal analysis based on the laboratory experimental Bench "FrictionInduced Vibration and noisE at Ecole Centrale de Lyon" (FIVE@ECL), Mechanical Systems and Signal Processing, $119,561-588,2019$.

doi.org/10.1016/j.ymssp.2018.07.006

\title{
Squeal analysis based on the laboratory experimental bench "Friction-Induced Vibration and noisE at École Centrale de Lyon"' (FIVE@ECL)
}

\author{
J-J. Sinou ${ }^{\mathrm{a}, \mathrm{b}, \mathrm{c}}$, D. Lenoir ${ }^{\mathrm{a}, \mathrm{d}}$, S. Besset ${ }^{\mathrm{a}, \mathrm{e}}$, F. Gillot ${ }^{\mathrm{a}, \mathrm{f}}$ \\ ${ }^{a}$ Laboratoire de Tribologie et Dynamique des Systèmes, UMR CNRS 5513, École Centrale de Lyon, 36 avenue Guy de Collongue 69134 \\ Écully Cedex, France \\ ${ }^{b}$ Institut Universitaire de France, 75005 Paris, France \\ ${ }^{c}$ jean-jacques.sinou@ec-lyon.fr \\ ddavid.lenoir@ec-lyon.fr \\ esebastien.besset@ec-lyon.fr \\ frederic.gillot@ec-lyon.fr
}

\begin{abstract}
This paper presents a new experimental test bench, called Friction-Induced Vibration and noisE at École Centrale de Lyon (FIVE@ECL). This experimental bench aims at discussing some of the open issues in understanding squealing disc brakes. Measurements for friction-induced vibration and squeal noise are performed to investigate the dynamic behavior of the system under study and its squeal characterization through experiments.

One of the main original contributions is to share the data sets to give the opportunity to researchers for conducting new analysis and testing numerical models of brake system with the proposed data of squeal noise. The data provided include all the measurements on the two pads, the caliper and the disc, as well as the measurement of sounds in near-field and in far-field.
\end{abstract}

Keywords: experiments, friction-induced vibration, squeal noise, brake system, open data.

\section{Introduction}

The prediction of self-excited vibration and acoustic radiation during squeal events are complex tasks that have been studied for many years. Nowadays it is recognized that brake squeal is a very complex phenomenon which generates a very annoying sound that affects the customer comfort. Despite considerable research into understanding and predicting brake squeal, the problem of squeal noise continues to be a major concern in numerous industrial applications related to automotive, aeronautic and railway fields. Even if it is admitted that the generation of squeal noise corresponds to a structural dynamics and tribological problem of the pad-disc brake system, explaining the generation of friction-induced vibration and noise as well as the squeal phenomena is not obvious and far from being fully understood. A fine and reliable understanding of brake squeal requires global expertise and advanced analysis

10 from various fields such as vibration, acoustics and tribology for example. Extensive reviews on this subject can be found in [1, 2, 3, 4, 5].

Industrial experimental tests have been widely performed in order to study brake squeal and more specifically to validate the design of brake assembly versus squeal phenomena in the fields of automotive [6, 7, 8, 9], railways [10, 11, 12, 13] or aeronautic [14, 15. On the other hand, academic research groups working on this subject proposed 15 to investigate brake squeal by developing academic simplified test rigs, one of the main reasons being to master the conditions of brake squeal vibration and noise. Experimental academic set-ups based on different configurations such as pad-on-disc [16, 17, 18, 19, beam-on-disc [20, 21, 22, 23, 24, or brake dynamometer [25, 26, have been developed in this direction. These studies on academic experimental set-ups are complementary studies to those conducted on industrial applications: one of the major assets of the development of such academic experimental benches is to be 20 able to acquire a clear understanding of the squeal mechanisms and then to extend such knowledge to control the squeal occurrence in commercial brakes.

Up to present, many test benches have been designed and used for squealing brake analysis. Each test bench has its own specificity for brake squeal analysis. Two main categories can be distinguished. Firstly some researchers Preprint submitted to Journal of $\mathrm{L}^{A} T_{E} X$ Templates 
[27, 28, 29, 30, 31, 32, 33, 34, 35, 36] approach the problem from a rather tribological point of view considering that

25 friction noise is a result of unstable vibration of frictional interface and so that the physical and chemical interface properties play significant roles in the occurrence of friction noise. Others prefer to characterize the friction-induced vibration through a global dynamical analysis of the brake system [8, 6, 17, 18, 21, 23, 24, 37, 38. The proposed study is rather part of this second category. Compared to the different existing test benches, one of the originality of the FIVE@ECL bench is to be able to undertake links between the self-excited vibrations of a squealing disc brake

so assembly and the generated squeal noise in near- or far-field. Moreover it can be noted that one of the main limitation of previously developed experimental set-ups interested in acoustic field is the use of a limited number of acoustic measurements. Indeed the acoustic responses is generally examined by using only one or two microphones which does not allow to reconstruct the radiated acoustic fiels pattern. Also in order to be able to both undertake links between the self-excited vibrations and squeal noise, and to reconstruct the acoustic pattern, the proposed test rig has been

35 designed by implementing more than 20 accelerometers and proximitors to capture the nonlinear dynamic of the pads, caliper and the disc and 15 microphones to capture the squeal noise. Additionally, one significant contribution of the proposed study is to provide reliable data for each component of the brake system and a complete measurement of both friction-induced nonlinear vibration and squeal noise. Until now no open data has yet been proposed by the scientific community for the subject of friction-induced noise and vibration and more specifically brake squeal. The

40 main interest of sharing open data for brake squeal is to promote accessible public data to solve complex problems for brake squeal and so that academic or industrial researchers can propose new analyze methods and develop numerical simulations in connection with free and reliable experimental data for brake squeal.

In order to fulfill this objective, this paper presents the new laboratory experimental bench Friction-Induced Vibration and noisE at École Centrale de Lyon (FIVE@ECL). Its design is the result of several years of work and 45 evolution of the initial design with the aim of performing reliable and robust experimental tests for studying squeal phenomenon in disc brakes and producing a variety of data for vibrational and acoustics measurements under controlled conditions. Moreover one of the main purpose is to propose a test bench capable of serving as an experimental tool to investigate the squeal characteristics for a specific brake system but also to analyze the squeal evolution with respect to different operational conditions and various designs of brake system. As a consequence, the design of the laboratory

so experimental bench FIVE@ECL is based on the assumption that the experimental protocol is mastered in order to obtain reliable data during experiments of squeal noise. This also implies the possibility to conduct reproducibility of the squeal conditions. If a set of operational parameters for a specific brake system produces a given squeal behavior in terms of vibration and acoustic measurement, the same specific behavior has to be reproduced by performing the controlled parameters on the same brake system.

This paper is organized as follows: the second section presents the general description and characteristics of the laboratory experimental bench FIVE@ECL. Then experimental analysis of brake squeal is proposed by using both vibrational measurements and radiated noise in near- and far-fields. Finally the potential of the laboratory experimental bench FIVE@ECL to provide repeatable and efficient experiments for squeal conditions is demonstrated.

\section{Description and main characteristics of the experimental bench FIVE@ECL}

One of the main purpose of the proposed experimental bench FIVE@ECL is to provide reliable data based on vibrational and acoustics measurements of a brake system during braking tests. For this purpose we propose to use the experimental bench FIVE@ECL as an investigative tool to correlate the dynamic behavior of different simplified brake systems with squeal characteristics. In order to fulfill such an objective, the dynamics of the brake system must be easily adjustable to study how changes affect squeal. As the propensity and characterization of friction-induced 6 vibration and squeal noise are directly dependent on the choice of both the pads, the disc and the caliper, it has been chosen to design the bench by considering a modular part (i.e. the simplified brake system) and a non-modular part that corresponds to the global frame support structure of the simplified brake system and elements for the implementation of braking tests.

In the following sections the global description and main characteristics of the experimental bench FIVE@ECL is 70 proposed. First of all, the non-modular part that corresponds to the experimental bench without the brake system and the instrumentation set-up is presented. Particular attention is paid to the motivation of its design. Secondly, a general description of the different types of usable simplified brake systems that can be mounted on the non-modular part of the bench is given. More specifically the main technical and operational choices are discussed. Finally the associated instrumentation and data acquisition process are presented.

\subsection{Design of the non-modular part of the experimental bench}

Three main motivations have been retained during the design and the development of the experimental bench FIVE@ECL. 


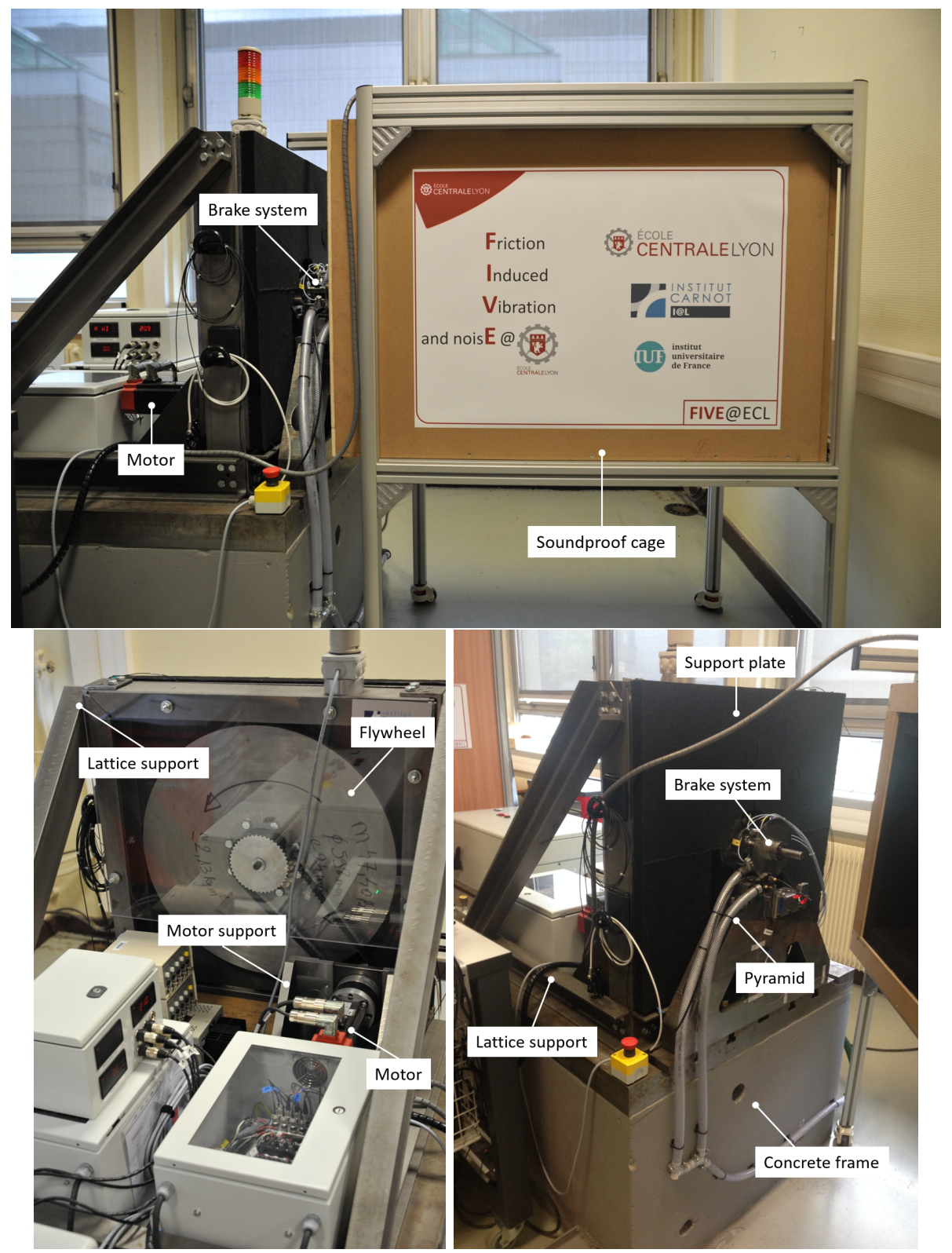

Figure 1: Experimental bench FIVE@ECL

First of all the principal aim is to study the intrinsic squeal phenomenon of simplified brake systems which can be reduced to a disc-pads-caliper system. Therefore it is essential to ensure that every support structures of the so simplified brake system do not affect the vibration behavior of the disc-pads-caliper system during braking and do not modify the squeal phenomenon when it appears and propagates. Consequently the experimental bench FIVE@ECL comprises two independent supports for the rotating and no-rotating elements of the brake system as indicated in Figures 1. the "pyramid" corresponds to the frame support for the caliper and the two pads; the "lattice support" corresponds to the frame support for the brake disc. These two supports have been designed as very massive and stiff

85 steel frames and are fixed to a large concrete frame in order to assure an efficient dynamic decoupling between these two elements. This design allows to avoid a transmission of parasitic vibration of the support structures during the squeal generation with a potential back loop on the squeal phenomenon that must be proscribed. Decoupling of the rigid support of the motor is also performed to avoid undesirable transmissions. The "motor support" is also visible in Figure 1 Moreover vibration damping plate that consists of a foam and a viscoelastic layer have been used to 90 absorb non desirable mechanical energy from the motor and drive elements of the brake system. This damping plate is placed directly on the "support plate" of the lattice support, as indicated in Figures 1. This damping plate fulfills two essential functions in order to greatly mitigate parasite vibration and noise on the squeal results: avoiding the 

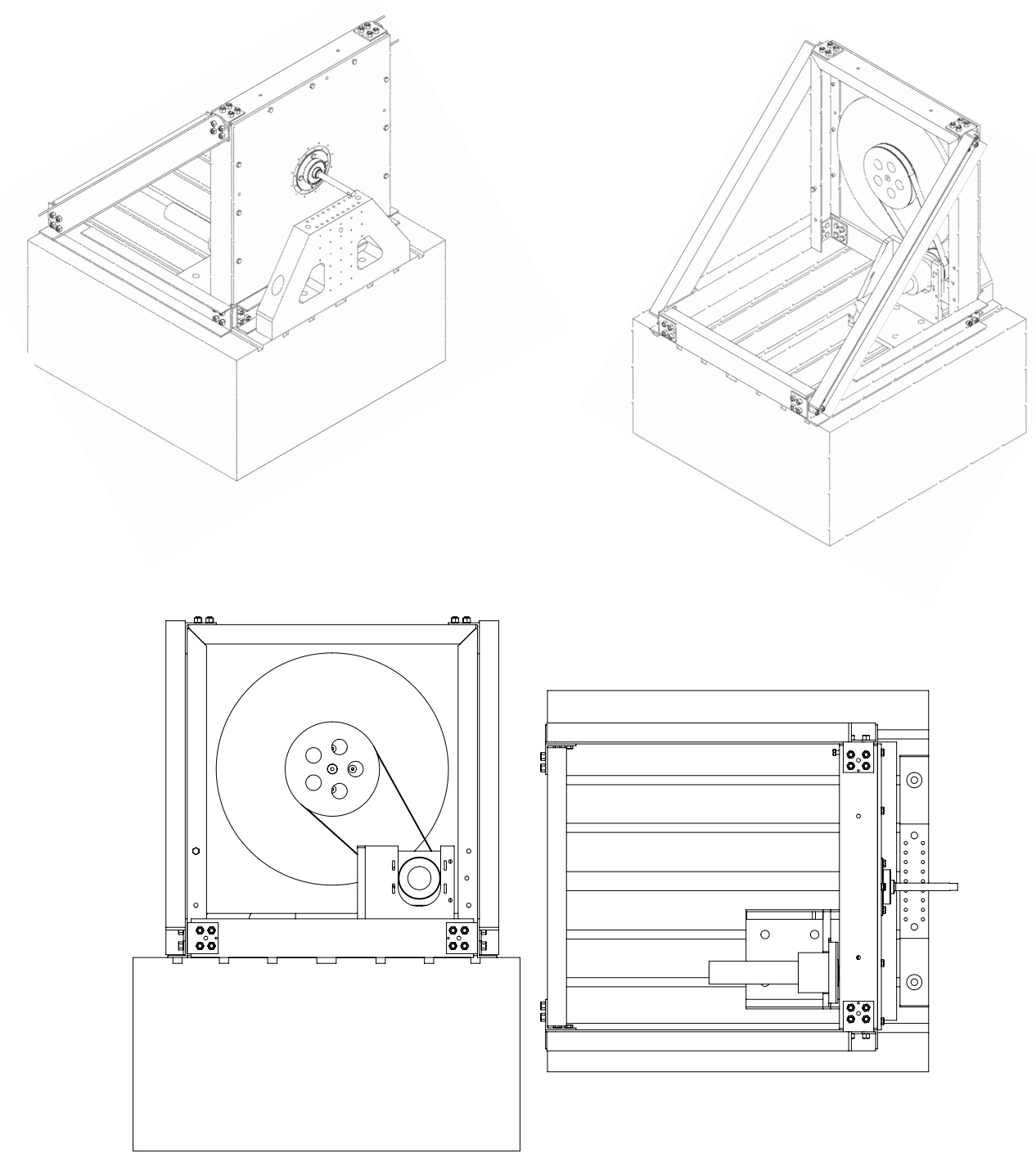

Figure 2: Schematic view of the bench Friction-Induced Vibration and noisE at Ecole Centrale de Lyon (FIVE@ECL) without the disc, the caliper and the two pads

propagation of the potential sound of the vibration modes of the support plate and limiting the effects of excitations of the motor via the belt and pulley system. Figure 2 gives the schematic view of the non-modular rigid supports of the experimental bench FIVE@ECL without showing the disk elements, the caliper and pads that can be interchangeable.

Secondly the test rig FIVE@ECL has been designed in order to investigate the problem of friction-induced vibration by considering both the vibration of the brake system and the generation of squeal sounds. Therefore the dynamic behavior of each part of the brake system (i.e. disc, shaft, pads, caliper, rigid supports,...) have to be measured appropriately to retrieve measurements throughout the system and its components that are necessary for squeal analysis. Information about squeal sounds in near-field and far-field are also essential in order to perform the characterization and understanding of squeal noise and also to make comparisons of identified vibratory and acoustic signatures. This specific point and more specifically the detail of all the experimental devices will be discussed in Section 2.3 .

Finally, the versatility of the test rig has also been taken into account during its design, and more particularly its ability to perform two specific braking tests :

- the classical transient braking test with decrease of the rotational speed of the disc that corresponds to a realistic braking event;

- the controlled braking test that consists of a test with a constant controlled rotational speed of the disc.

As previously explained in [13, experimental investigation and understanding of squeal noise for industrial systems 
is a nontrivial issue due to the high complexity of real brake system and the difficulty to perform repeatable mea110 surements due to the possibility of dispersion of data during experimental tests. To avoid the difficulty arising from a realistic braking test based on a transient braking test with a normalized decrease of the rotational speed of the disc, experimental tests can be performed by considering a controlled steady rotational speed. This choice is based on the assumption that simplifying the experimental protocol is necessary in order to obtain reliable data during experiments and so to be able to better control the conditions of occurrence of squeal and so to characterize its signature. One of

115 the assumptions of such a process is that one considers that squeal behavior can be generated without a variation of the rotation speed or can fluctuate on a much faster time-scale than sliding speed changes. These considerations have mainly impacted the choice of the motor's characteristic and the associated drive-elements :

- the maximal delivered motor's torque must be able to overcome the maximal brake torque in order to fulfill the controlled braking test squeal requirements;

- the electric motor allows a fast return to the nominal rotational speed at the beginning of the contact between pads and disc without significant fluctuation of rotational speed in order to avoid fluctuations of friction-induced vibration and squeal noise due to the decrease of the rotational speed;

- the test rig must include an inertial flywheel to store some rotational kinetic energy equivalent to the translational kinetic energy required by the classical transient braking test.

The motor regulation is performed by a high performance PID controller which allows a nearly constant speed, even in case of fast brake torque variations.

\subsection{Main technical choices for the modular simplified brake systems}

As previously explained one of the main originality of the proposed experimental bench FIVE@ECL is to be able to study different types of simplified brake systems by adapting them directly on the non-modular part of the experimental bench that has been described in Section 2.1 .

However, the potential brake systems have to meet the following technical requirements:

- one fixed non-floating caliper with two pads;

- one disc for which the outer diameter can be chosen to be between $0.16 m$ and $0.2 m$;

- compatibility with the motor limitations: mainly a nominal torque of $25 N . m$, a peak torque of $60 N . m$, and maximal rotating speed of 500rpm.

Therefore various calipers and pads coming from manufacturers, and more specifically from the mountain bike brake community, can be easily adapted on the experimental bench. The disc can be custom made or correspond to a classical commercial disc like for example mountain bike discs.

One of the main advantages of being able to test in the future several types of braking systems is that the propensity and characterization of friction-induced vibration and noise could be investigated by considering not only the influence of tribological considerations at the frictional areas between pads and disc, but also by performing structural modifications on the three main components which inevitably leads to modifications of the vibratory behavior of the brake system. It can be noted that the test rig has not been specifically designed to thoroughly investigate tribological and thermal aspects at the frictional interface. So the influence of tribological factors on friction-induced vibration and noise will be limited to the study of the impact of an apparent coefficient of friction and its potential evolution during a test.

Considering more specifically the implementation of the brake system on the non-modular part of the experimental bench FIVE@ECL, the disc is fixed on a $0.025 \mathrm{~m}$ diameter steel shaft that is mounted on the support plate by two bearings. A steel flywheel of $0.6 \mathrm{~m}$ outer diameter, weighting $50 \mathrm{~kg}$ and with a rotational inertia of $2.2 \mathrm{~kg} . \mathrm{m}^{2}$ is also 150 mounted on this shaft. The braking is activated by a manual hydraulic pump, for a typical pressure going from 0 to 15 bars. This braking application causes pressing brake pads against disc and so induces friction between pads and disc, and so potential squeal events.

Several choices are made on the operating conditions of a braking test. First of all, experimental tests are performed under dry conditions even if it is well-known that wet experiments conditions considerably affect the occurrence and the intensity of brake squeal in real conditions. Secondly, remembering that brake principle consists to convert kinetic energy to thermal energy, monitoring and controlling temperature at the friction interfaces between pads and disc appears to be an important point. For the sake of simplicity, pad's temperature is monitored but the temperature is not controlled during a braking test. It should be mentioned that an automatic emergency stop switch off the motor when pad's temperature is greater than $75^{\circ} \mathrm{C}$ so that over-heating of the instrumentation is avoided. 


\begin{tabular}{|c|c|c|c|c|c|c|c|c|}
\hline ID & Name & Units & Partname & $\begin{array}{l}\text { Xpos } \\
(\mathrm{mm})\end{array}$ & $\begin{array}{l}\text { Ypos } \\
(\mathrm{mm})\end{array}$ & $\begin{array}{l}\text { Zpos } \\
(\mathrm{mm})\end{array}$ & $\begin{array}{l}\text { Global } \\
\text { frame }\end{array}$ & $\begin{array}{l}\text { Local } \\
\text { frame }\end{array}$ \\
\hline 1 & TriAxe.1.X & $\mathrm{g}$ & Rear pad & -45 & -90 & -10 & $-\mathrm{Z}$ & $\mathrm{X}_{1}$ \\
\hline 2 & TriAxe.1.Y & $\mathrm{g}$ & Rear pad & -45 & -90 & -10 & $\mathrm{XY}$ & $Y_{1}$ \\
\hline 3 & TriAxe.1.Z & $\mathrm{g}$ & Rear pad & -45 & -90 & -10 & $\mathrm{XY}$ & $\mathrm{Z}_{1}$ \\
\hline 4 & TriAxe.2.X & $\mathrm{g}$ & Rear pad & -25 & -100 & -10 & $-Z$ & $\mathrm{X}_{2}$ \\
\hline 5 & TriAxe.2.Y & $\mathrm{g}$ & Rear pad & -25 & -100 & -10 & $\mathrm{XY}$ & $\mathrm{Y}_{2}$ \\
\hline 6 & TriAxe.2.Z & $\mathrm{g}$ & Rear pad & -25 & -100 & -10 & $\mathrm{XY}$ & $\mathrm{Z}_{2}$ \\
\hline 7 & TriAxe.3.X & $\mathrm{g}$ & Front pad & -25 & -100 & 10 & $+\mathrm{Z}$ & $\mathrm{X}_{3}$ \\
\hline 8 & TriAxe.3.Y & $\mathrm{g}$ & Front pad & -25 & -100 & 10 & $\mathrm{XY}$ & $\mathrm{Y}_{3}$ \\
\hline 9 & TriAxe.3.Z & $\mathrm{g}$ & Front pad & -25 & -100 & 10 & $X Y$ & $\mathrm{Z}_{3}$ \\
\hline 10 & TriAxe.4.X & $\mathrm{g}$ & Front pad & -45 & -90 & 10 & $+\mathrm{Z}$ & $\mathrm{X}_{4}$ \\
\hline 11 & TriAxe.4.Y & $\mathrm{g}$ & Front pad & -45 & -90 & 10 & $\mathrm{XY}$ & $\mathrm{Y}_{4}$ \\
\hline 12 & TriAxe.4.Z & $\mathrm{g}$ & Front pad & -45 & -90 & 10 & $\mathrm{XY}$ & $\mathrm{Z}_{4}$ \\
\hline 13 & TriAxe.5.X & $\mathrm{g}$ & Caliper & -25 & -70 & 20 & $+\mathrm{Z}$ & $\mathrm{X}_{5}$ \\
\hline 14 & TriAxe.5.Y & $\mathrm{g}$ & Caliper & -25 & -70 & 20 & $+\mathrm{Y}$ & $\mathrm{Y}_{5}$ \\
\hline 15 & TriAxe.5.Z & $\mathrm{g}$ & Caliper & -25 & -70 & 20 & $-\mathrm{X}$ & $Z_{5}$ \\
\hline 16 & Micro.1 & $\mathrm{Pa}$ & Antenna (FF) & -200 & -200 & 330 & - & - \\
\hline 17 & Micro.2 & $\mathrm{Pa}$ & Antenna (FF) & 0 & 200 & 330 & - & - \\
\hline 18 & Micro.3 & $\mathrm{Pa}$ & Antenna (FF) & 200 & 200 & 330 & - & - \\
\hline 19 & Micro.4 & $\mathrm{Pa}$ & Antenna (FF) & -200 & 0 & 330 & - & - \\
\hline 20 & Micro. 5 & $\mathrm{~Pa}$ & Antenna (FF) & 0 & 0 & 330 & - & - \\
\hline 21 & Micro.6 & $\mathrm{Pa}$ & Antenna (FF) & 200 & 0 & 330 & - & - \\
\hline 22 & Micro.7 & $\mathrm{Pa}$ & Antenna (FF) & -200 & -200 & 330 & - & - \\
\hline 23 & Micro. 8 & $\mathrm{~Pa}$ & Antenna (FF) & 0 & -200 & 330 & - & - \\
\hline 24 & Micro.9 & $\mathrm{Pa}$ & Antenna (FF) & 200 & -200 & 330 & - & - \\
\hline 25 & Micro.10 & $\mathrm{Pa}$ & Caliper support (NF) & 10 & -110 & 30 & - & - \\
\hline 26 & Micro.11 & $\mathrm{Pa}$ & Antenna (FF) & -100 & 100 & 330 & - & - \\
\hline 27 & Micro.12 & $\mathrm{Pa}$ & Antenna (FF) & 100 & 100 & 330 & - & - \\
\hline 28 & Micro.13 & $\mathrm{Pa}$ & Antenna (FF) & -100 & -100 & 330 & - & - \\
\hline 29 & Micro.14 & $\mathrm{Pa}$ & Antenna (FF) & 100 & -100 & 330 & - & - \\
\hline 30 & Micro.15 & $\mathrm{Pa}$ & Caliper support (NF) & 110 & -110 & 30 & - & - \\
\hline 31 & Proxy.1 & $\mathrm{mm}$ & Disc & 64 & -38 & 0 & $+\mathrm{Z}$ & - \\
\hline 32 & Proxy.2 & $\mathrm{mm}$ & Disc & 37 & 64 & 0 & $+\mathrm{Z}$ & - \\
\hline 33 & Proxy.3 & $\mathrm{mm}$ & Disc & -49 & 57 & 0 & $+\mathrm{Z}$ & - \\
\hline 34 & Proxy.4 & $\mathrm{mm}$ & Disc & -71 & -26 & 0 & $+\mathrm{Z}$ & - \\
\hline 35 & RotationSpeed & $\mathrm{rpm}$ & - & - & - & - & - & - \\
\hline 36 & Torque & $\mathrm{Nm}$ & - & - & - & - & - & - \\
\hline 37 & BrakePressure & bar & - & - & - & - & - & - \\
\hline 38 & BrakeTemperature & ${ }^{\circ} \mathrm{C}$ & - & - & - & - & - & - \\
\hline
\end{tabular}

Table 1: List of the experimental device: channel number and position of each sensor (FF: Far Field; NF: Near Field)

Finally a vacuum cleaner has been implanted in order to dispose as much as possible the wear debris accumulation that occurs on the disc/pad surfaces and in the vicinity of the brake system and the transducers. It also helps to quickly decrease the temperature at the end of a braking test in order to come back to the initial temperature condition and so to reduce the time delay between two consecutive braking tests. This system is obviously not active during a braking test in order to avoid the noise perturbation generated by this vacuum cleaner.

\subsection{Instrumentation and data acquisition}

The brake system is fully instrumented. Different types of transducers (such as accelerometer, proximity sensor, microphone, pressure sensor, thermocouple, torque meter and speed sensor) are used to capture all the operational parameters and to measure the static position and dynamic vibration values. The complete list of the experimental measurement devices is as follows:

- Four miniature triaxial Integrated Electronic Piezo-electric (IEPE) accelerometers are placed on the two pads, i.e. two accelerometers for each pad with three independent outputs for simultaneous measurements on the x-, 


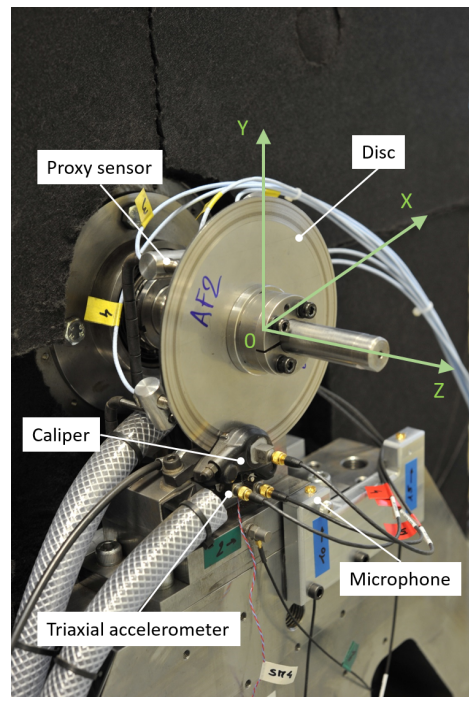

(a)

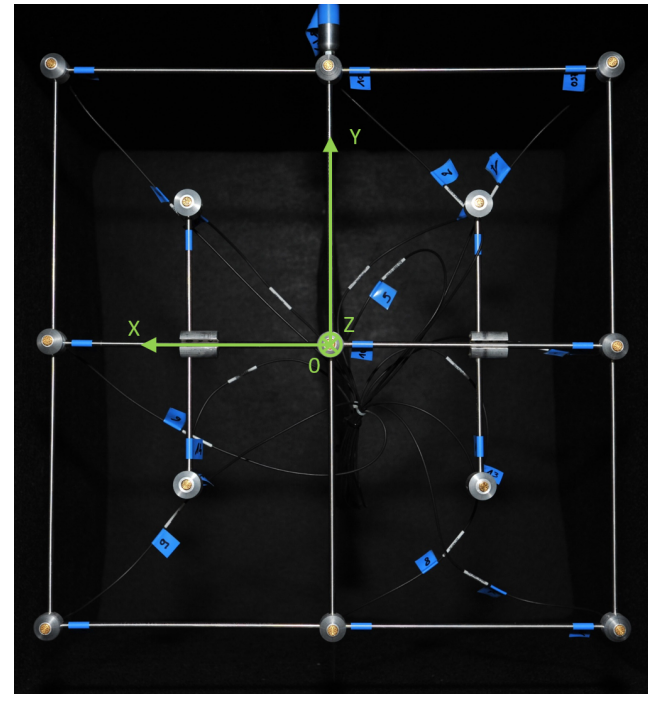

(b)

Figure 3: Experimental measurement devices of the experimental bench

y- and z-axes for each accelerometer. These accelerometers have the peculiar to be very small and lightweight (it weighs less than 3 grams) that make them ideal for measurements on light structures. The permissible temperature range of these accelerometers during experiments is between $[-51 ;+121]^{\circ} C$. This will make it possible to carry out measurements on the brake pads during a braking even if this component heats during the test (ref. Bruël \& Kjær Miniature Triaxial DeltaTron@Accelerometer - Type 4520).

- One miniature triaxial Integrated Electronic Piezo-electric (IEPE) accelerometer is also placed on the brake caliper (ref. Bruël \& Kjær Miniature Triaxial DeltaTron@Accelerometer - Type 4520).

- Four miniature DeltaTron Accelerometers are mounted on different parts of the frame structure of the bench to ensure that the external bench structures do not vibrate and therefore do not cause parasitic vibratory phenomena in the squeal measurements (ref. Bruël \& Kjær Miniature DeltaTron@Accelerometer - Type 4397A).

- Fifteen prepolarized microphones suited to non-stationary measurements have also been implemented on the test bench (ref. Bruël \& Kjær 20kHz Prevision Array Microphone - Type 4958). Two of them are mounted close to the brake system to perform measurements in near-field. One antenna with the other thirteen microphones is placed in front of the brake system to perform measurements in far-field in the direction normal to the brake system (see Figures $3(\mathrm{a})$ ). The position of the antenna with respect to the disc is adjustable between $[0.3 ; 1] \mathrm{m}$. Moreover this antenna is placed in a specific soundproof cage that has been designed to avoid and reduce unwanted noise for acoustic measurement and analysis. This allows a fine characterization of squeal sounds with low level of noise. One sound absorption foam that consists of a foam insulation and a viscoelastic layer is also put to the back and on each side of the cage. Experimental tests using impulse acoustic excitations have been carried out to validate that the acoustic remains acceptable until about $500 \mathrm{~Hz}$. In other words, this foam insulation allows to prevent the cage's walls from reflecting or transmitting sound and so acting like a sound amplifier. As a consequence, this only leaves the front side of the cage exposed for the propagation of the squeal noise. In order to have the most perfect acoustic measurements in the far field and to avoid undesirable disturbance on the squeal analysis, no physical object or measurement device is positioned between the brake disc and the acoustic antenna.

- Six proximitor sensors are used to perform vibration measurements on the rotating parts of the bench (ref. Bently Nevada 3300 XL NSv). These non-contact displacement transducers provides an output voltage that is directly proportional to the distance between the probe tip and the observed conductive surface of the shaft or the disc. It allows to measure both static position and dynamic vibration values. The vibration measurements of the shaft are conducted by using two proximity probes that are mounted in the horizontal and vertical directions as shown in Figures 3(a). The other four proximitor sensors are positioned facing the surface of the disc and being uniformly distributed in order to measure the static sliding equilibrium position and the disc vibrations in the normal direction. They allows to perform static and dynamic measurements even if the disc surface has 
a high temperature due to braking and friction between pads and disc, since the probe temperature range is between $[-51 ;+177]^{\circ} \mathrm{C}$.

Even if the transducers have be chosen to be as light as possible it is obvious that the presence of the miniature accelerometers mounted on the pads and the caliper may modify the structural dynamic of the brake system. This implies that adding a lumped mass to model each transducer has to be done in numerical models in order to correlate as well as possible experiments and numerical simulations. Moreover to allow comparison of experiments with and without these accelerometers it is necessary to add equivalent additional lumped masses instead of transducers. This will be more particularly necessary for high temperature tests for which the trixial accelerometers mounted on the pads have to be removed. Thus the structural vibratory signature of the brake system will be identical in both configurations. In addition preliminary studies have been performed to verify that the transducers mounted on the different parts of the frame structure do not affect the vibratory signature of brake squeal. It should also be noted that the four miniature accelerometers mounted on different parts of the frame structure and the two proximitor sensors placed at the shaft are only used to ensure that there is no significant parasitic vibration compared to the frictioninduced vibration of squeal events. Therefore these measurements are not used for the analysis of squeal vibration and noise.

As previously explained in Section 2.1 the design of FIVE@ECL has been conducted so that each of its components can be accessible by instrumentation while ensuring that the devices for vibrational measurements do not interfere with the generation and propagation of the squeal acoustic measurements. More specifically, this leads to the fact that the proximity sensors measuring the normal displacement of the disc do not interfere with the measurement of the radiated sound via the microphones. So the proximity sensors are arranged close to one side of the surface of the disc and the microphones are positioned relative to the other side of the disc as shown in Figure 3.

Table 1 summarize all the channel measurements of the experimental bench and the position of each sensor. The global coordinate system is referenced at the center of the disc and shown in green on Figures 3. Some experimental devices of the experimental bench FIVE@ECL can also be seen on Figures 3.

Furthermore four operational parameters such as the pressure (i.e. the normal load applied on the pads), the rotating speed of the disc, the motor torque and the temperature close to the pad/disc brake system are captured during experiments. The pressure and the rotating speed of the disc are two controllable parameters during experiments whereas the motor torque and the temperature are uncontrolled parameters resulting directly from the specificity of the braking test. One thermocouple is placed on one pad to monitor the temperature change in the vicinity of one of the two friction zones during braking. As previously indicated in Section 2.2, this temperature monitoring is performed to preserve the integrity of the sensors while keeping a safety margin by allowing an emergency stop when the measured temperature becomes greater than $75^{\circ} \mathrm{C}$.

All the dynamic signal acquisition are performed via the data acquisition platform CompactDAQ from National instrument that control timing, synchronization and data transfer between the Sensor-Based Input/Output modules and the external host. The hardware driver (i.e. communication between the PC and the data acquisition platform device), the software control and development environments (such as visualize and log data) are homemade via Matlab software. The sampling rate of each channel of the data acquisition system is $25600 S . s^{-1}$ with a 24-bit resolution. This choice is consistent with the objective of capturing a sound pressure level signal of $10 \mathrm{kHz}$ maximum frequency and the acceleration signal of $10 \mathrm{kHz}$ maximum frequency. The limitation of the acquisition frequency band is therefore defined by the performance of each sensor.

\section{Configuration of the present study}

\subsection{Selected design of the brake system under study}

In the present paper, the three main elements selected for the study of the brake squeal are as follows:

- the disc is homemade one with a $0.16 \mathrm{~m}$ external diameter, $0.034 \mathrm{~m}$ internal diameter and a thickness of $0.002 \mathrm{~m}$. It is made by using X2CrNi18-9 inox steel. The density is $7900 \mathrm{~kg} \cdot \mathrm{m}^{-3}$ and the elastic modulus is $200 \mathrm{GPa}$ at $20^{\circ} \mathrm{C}$. Without the mounting parts, it weighs $0.31 \mathrm{~kg}$

- the caliper corresponds to the reference XT M785 Disc Brake Caliper from the japan manufacturer Shimano. It is composed of a forged caliper monobody with two opposed $22 \mathrm{~mm}$ ceramic pistons. In service (i.e. wtih internal fluid and a $1.5 \mathrm{~m}$ length hose), it weighs about $0.12 \mathrm{~kg}$.

- the two disc brake pads are the reference F03C from the japan manufacturer Shimano. Each pad has a frictional area of approximatively $3.910^{-4} \mathrm{~m}^{2}$. It is composed of a $2 \mathrm{~mm}$ thickness aluminium backplate with a $2 \mathrm{~mm}$ thickness friction body of sintered metal. In order to clarify the correct chemical composition of the sintered 


\begin{tabular}{cccccccccccc} 
Element & $\mathrm{O}$ & $\mathrm{Al}$ & $\mathrm{Si}$ & $\mathrm{Ca}$ & $\mathrm{Cr}$ & $\mathrm{Fe}$ & $\mathrm{Cu}$ & $\mathrm{Zn}$ & $\mathrm{Zr}$ & $\mathrm{Sn}$ & $\mathrm{Ta}$ \\
\hline wt\% & 15.14 & 5.43 & 4.7 & 5.7 & 2.62 & 1.25 & 52.83 & 5.69 & 3.05 & 1.67 & 1.91 \\
wt\% sigma & 0.26 & 0.13 & 0.16 & 0.12 & 0.1 & 0.1 & 0.5 & 0.25 & 0.25 & 0.18 & 0.62 \\
\hline
\end{tabular}

Table 2: Chemical composition of the friction body of the pad (percentage by weight)

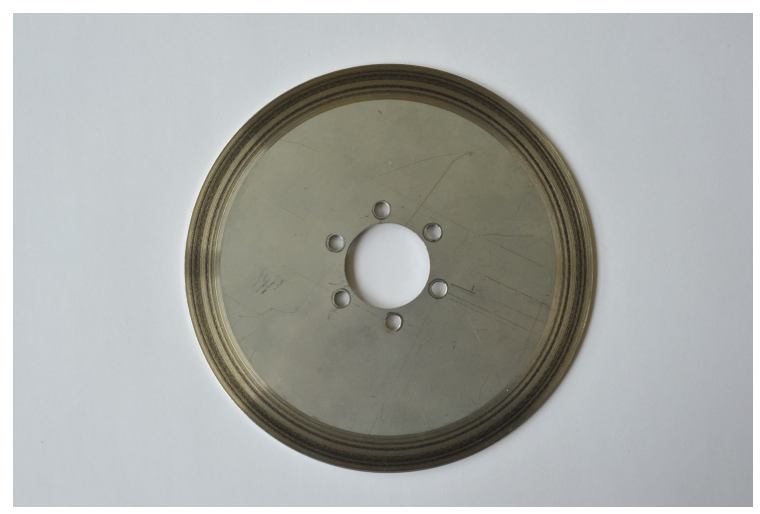

(a)

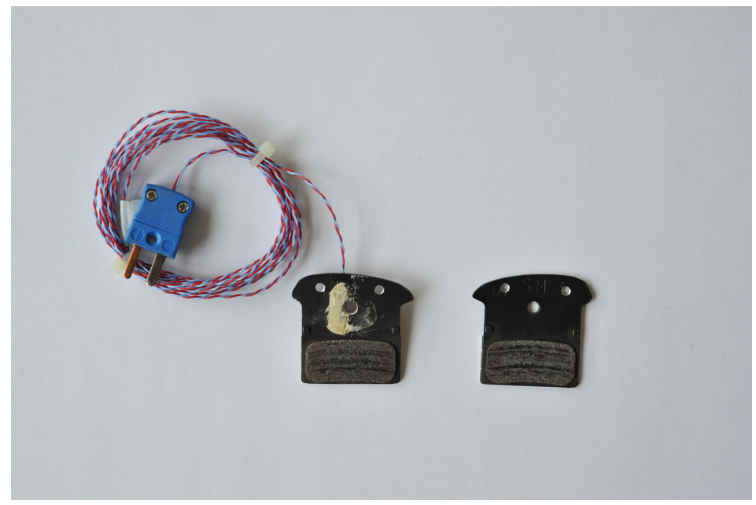

(c)

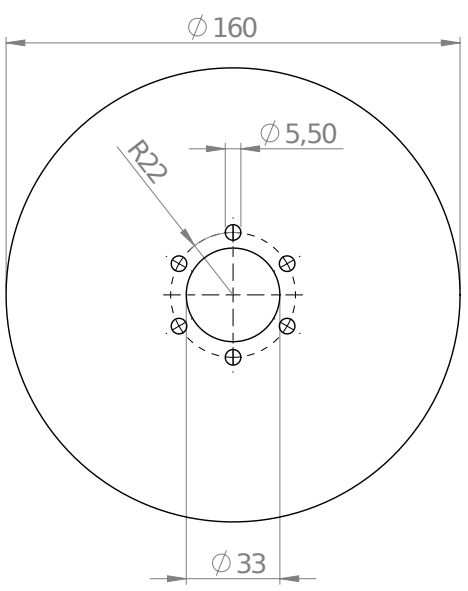

$\underline{2}$

(b)

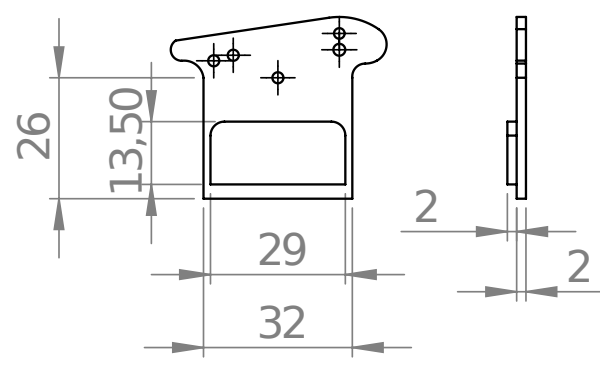

(d)

Figure 4: Visualization of the brake under study (a) homemade disc and (c) Shimano F03C brake pads ; engineering drawings of (b) the disc and (d) one pad

metal, a sample of the friction body is analyzed by Scanning Electron Microscopy (SEM). The results obtained are shown in Table 2 ,

These choices for the material properties of the disc and the pads type are guided by a strong squeal propensity for this brake assembly. Therefore they are not chosen with respect to a specific industrial application. Figures 3 show the complete brake system and Figures 4 illustrate more specifically the homemade disc and two Shimano brake pads with engineering drawings of one pad and the disc.

\subsection{Response of the no-rotational coupled system without friction}

This section investigates the dynamic behavior of selected brake system when the disc does not rotate. The configuration called "coupled system"' considers that the two pads and the disc are in contact applying a pressure force (without friction or rotation of the system). This first test is used to provide the reference behavior of the laboratory brake system FIVE@ECL before performing braking tests.

Excitation of the coupled system is performed by impacting the normal surface of the disc at several physical points with a shock-hammer. This experiment is reproduced several times according to various pressure force and for several positions of the disc. This analysis makes it possible more particularly to bring out the modes of coupled system which involve the vibratory contributions of the disc, pads and caliper. 


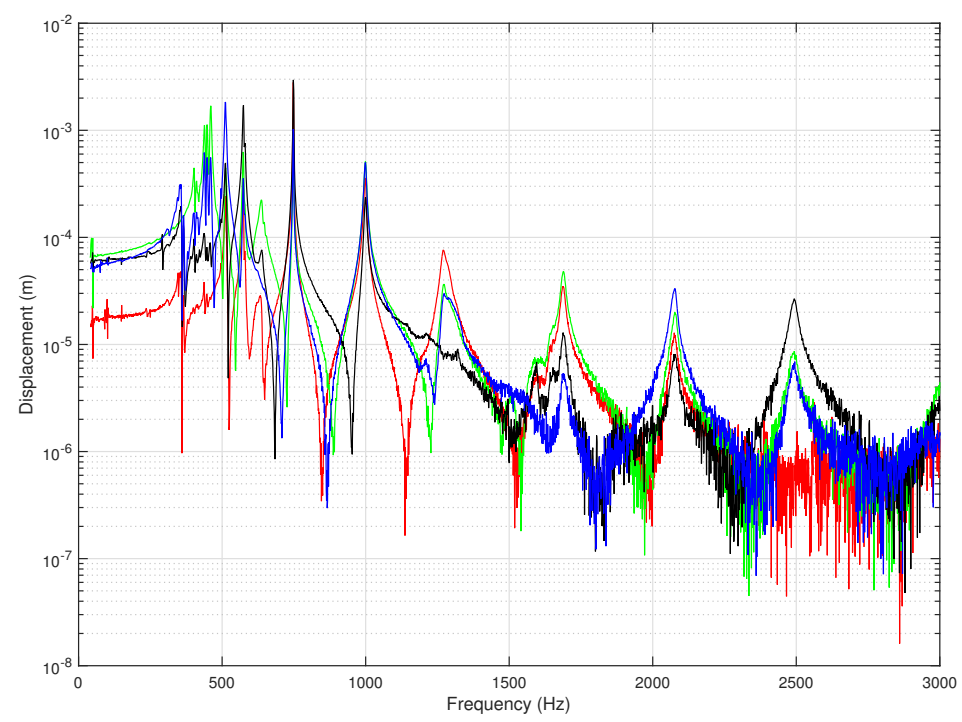

Figure 5: Response and frequency peaks of the no-rotational coupled system : black=Proxy.1, green=Proxy.2, blue=Proxy.3, red $=$ Proxy .4

Figure 5 shows different responses of the coupled system that exhibit frequency peaks by doing one shock hammer test at the location of each proximity sensor. The identified frequencies of the coupled system for all the modes in the frequency range $[100 ; 3000] \mathrm{Hz}$ are $440 \mathrm{~Hz}, 450 \mathrm{~Hz}, 460 \mathrm{~Hz}, 510 \mathrm{~Hz}, 575 \mathrm{~Hz}, 635 \mathrm{~Hz}, 750 \mathrm{~Hz}, 1000 \mathrm{~Hz}, 1270 \mathrm{~Hz}, 1690 \mathrm{~Hz}$, $2080 \mathrm{~Hz}$ and $2500 \mathrm{~Hz}$.

The repeatability of the tests has also been verified. These test results and measurements provide a reference behavior: they may serve as a basis to extract the contributions of the brake system for the following observations on the dynamic behavior during squeal events, even if the rotation of the disc and the notion of sliding friction are not present in this characterization of the coupled system.

\section{Squeal analysis of a controlled braking test}

\subsection{Experimental procedure for the proposed study}

In the following, the "controlled braking test" process is chosen with a constant rotational speed around $200 \mathrm{rpm}$ and a pressure around 9bars. The antenna with the thirteen microphones is placed at 0.33 meter from the braking system.
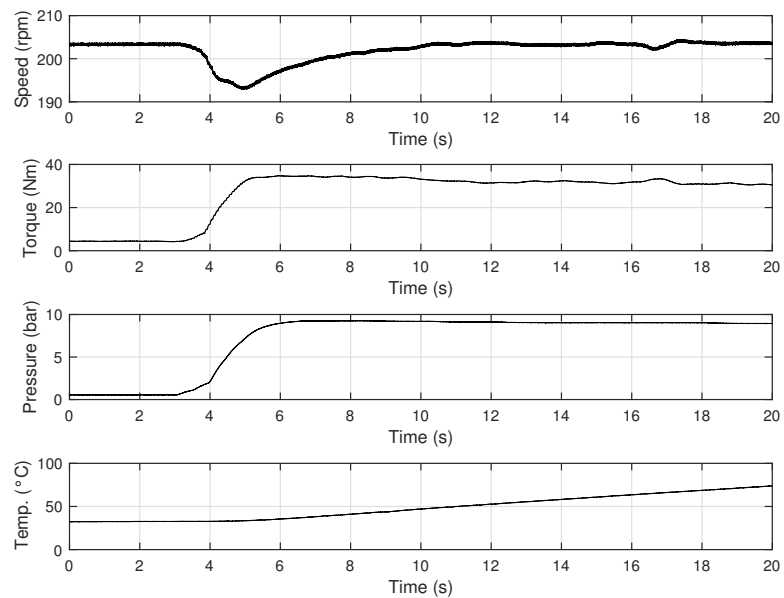

Figure 6: Time responses of the four operational parameters: the speed rotation of the disc, the motor torque, the brake pressure and the temperature) 

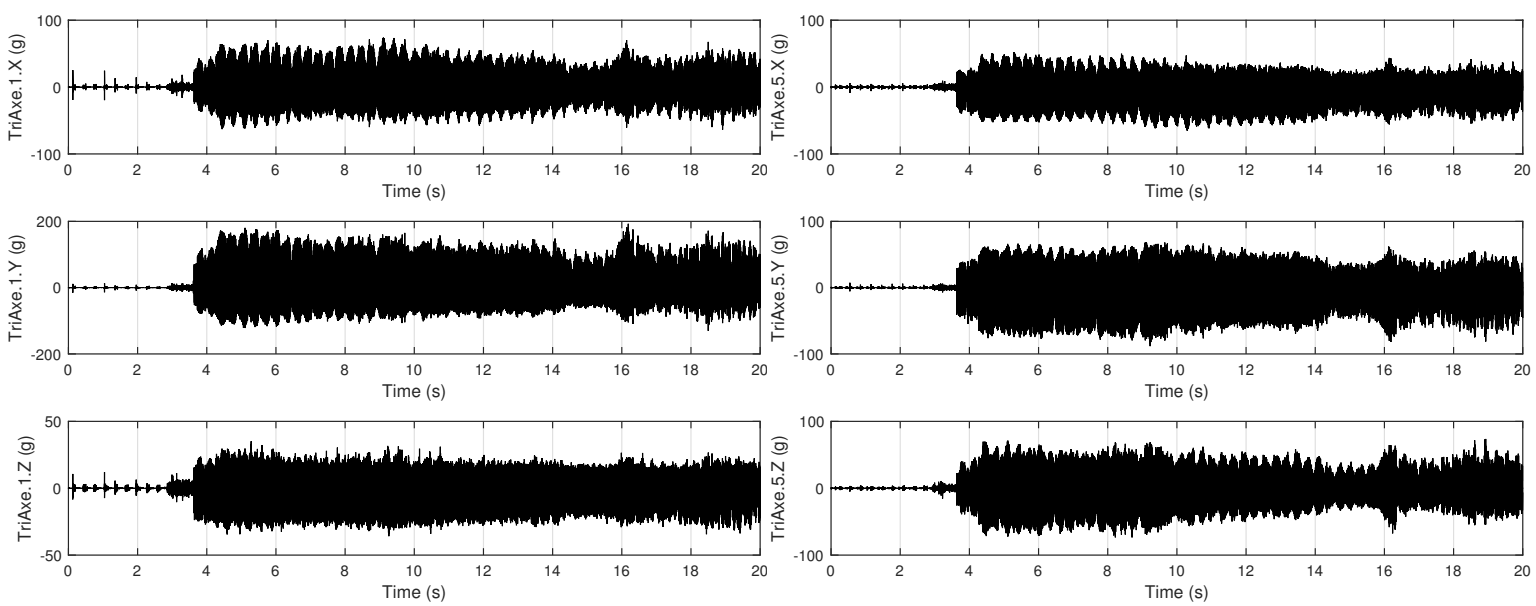

(a)

(b)

Figure 7: Time responses on the (a) pad in the local frame $\left(X_{1}, Y_{1}, Z_{1}\right)$ (b) caliper in the local frame $\left(X_{5}, Y_{5}, Z_{5}\right)$
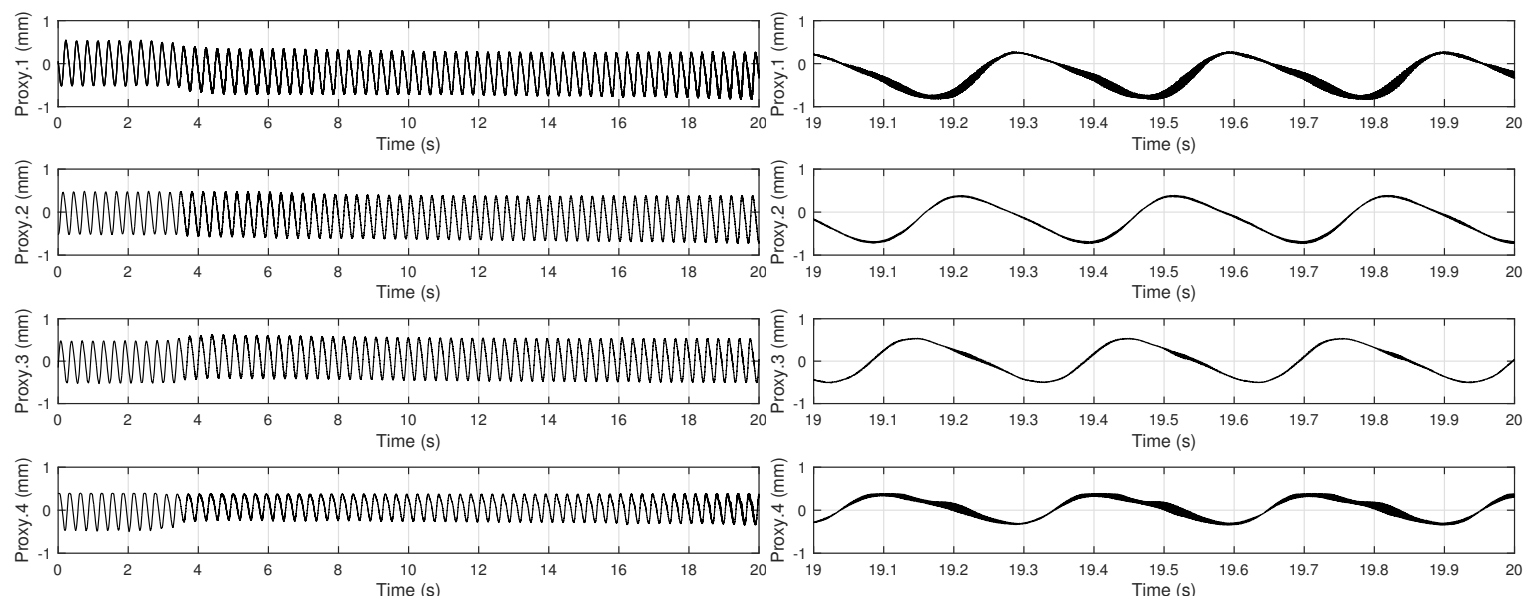

(a)

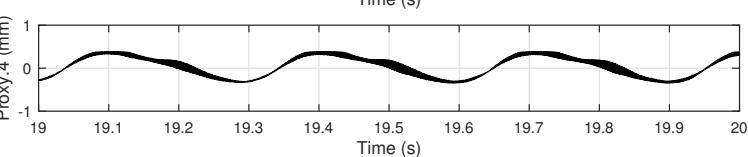

(b)

Figure 8: Time responses of the normal displacements of the disc for (a) $t=[0 ; 20] s$ (b) zoom for $t=[19 ; 20] s$

The braking test can be decomposed as follow:

- Phase 1: an initial phase with a duration between 2 and 3 seconds for which the system runs at the chosen constant speed without braking. This first phase allows to identify the initial test control level without braking. So friction-induced vibration and squeal noise during braking can be compared and analyzed versus the initial vibrational conditions.

- Phase 2: the second phase with a duration between 3 and 4 seconds corresponds to a transient braking behavior before the specificity of the "controlled braking test".

- Phase 3: the last phase correspond to the braking test with the stabilization of the constant rotational speed. Squeal characteristics based on vibrational and acoustics measurements are performed during this last phase.

All the raw data of Case 1 including the measurements on the two pads, the caliper and the disc, as well as the measurement of sounds in near-field and in far-field are available on [39.

\subsection{Time domain analysis}

Figures 6 give the evolution of the four operational parameters (i.e. the speed rotation of the disc, the motor torque, the brake pressure and the temperature) during the braking test. The three phases previously described in Section 4.1 can be clearly distinguished. 

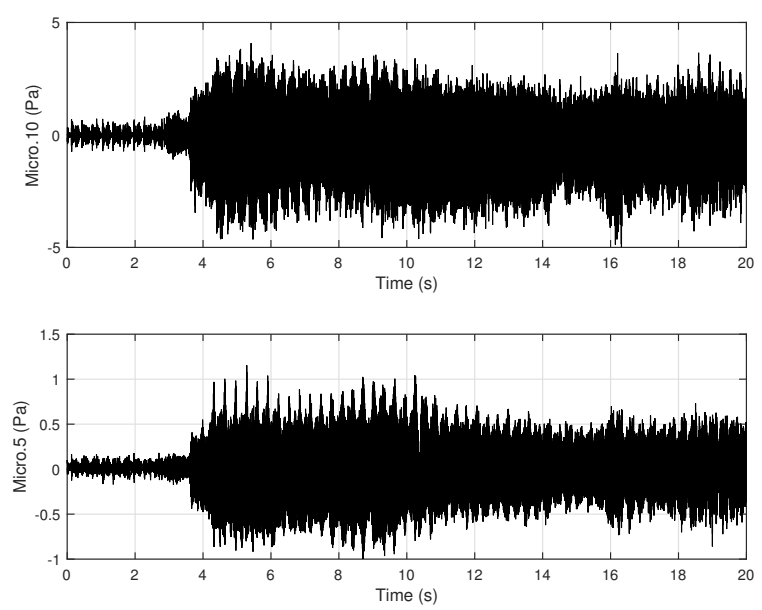

Figure 9: Time response of the squeal noise in near-field and far-field

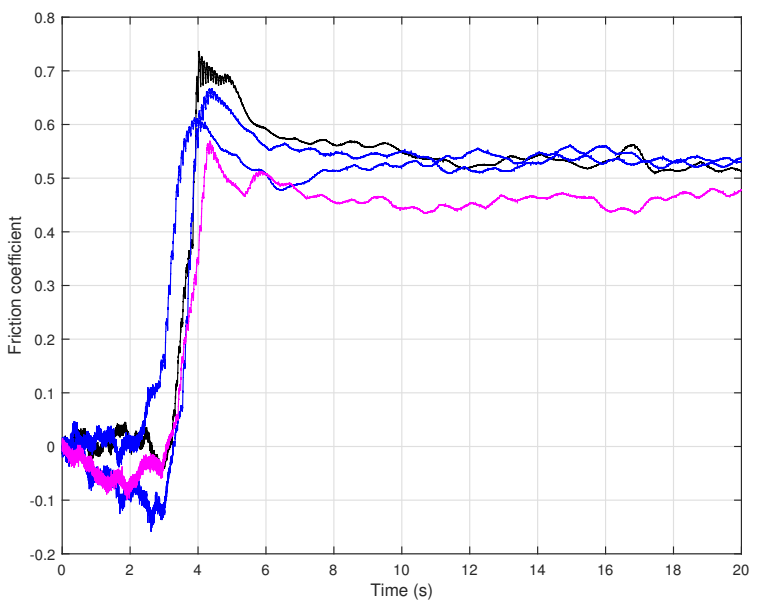

Figure 10: Estimation of this instantaneous friction coefficient during a braking test $($ black $=$ Case 1 ; blue $=$ Cases 2 ; red $=$ Case 3 )

At the beginning of the experimental test (for $t=[0 ; 3] \mathrm{s}$ ), the braking system rotates at a constant rotational speed without contacts between the pads and the disc. Between $t=[3 ; 5] s$ a pressure force is applied putting in contact the two pads with the disc (on each planar side of the disc).

It is observed that the motor fulfills its role as speed regulator by maintaining a constant speed throughout the test at around 200rpm. A very small variation in speed is observed when contacts between the disc and the pads occur, but the latter is very quickly compensated by the motor. Moreover the motor torque increases with the pressure increase and then stabilizes. Both the motor torque and the rotational speed remain practically unchanged throughout the braking. Then the evolution of the temperature in the vicinity of one pad is characterized by a regular continuous increase. This can be explained by maintaining the brake system under pressure which induces a progressive heating of the pads by friction. Care was taken to ensure the repeatability of the evolution of these four operational parameters during braking tests. These demonstrate the effectiveness of the laboratory experimental bench in order to have controlled and robust operating conditions.

Figures 7, 8 and 9 give the transient nonlinear responses of:

- the measurements of acceleration on one pad (see Figure 7(a)),

- the measurement of acceleration on the caliper (see Figure 7(b)),

- the normal displacements of the disc (see Figures 8),

- and the measurement of sounds in near-field and in far-field (see Figures 9).

For each sensor of the pad and caliper, it can be seen that the signal is almost zero before braking (for $t=[0 ; 3] s)$. At the beginning of braking, as soon as the disc and the pads are in contact for $t=[3 ; 4] s$, the time responses increase 


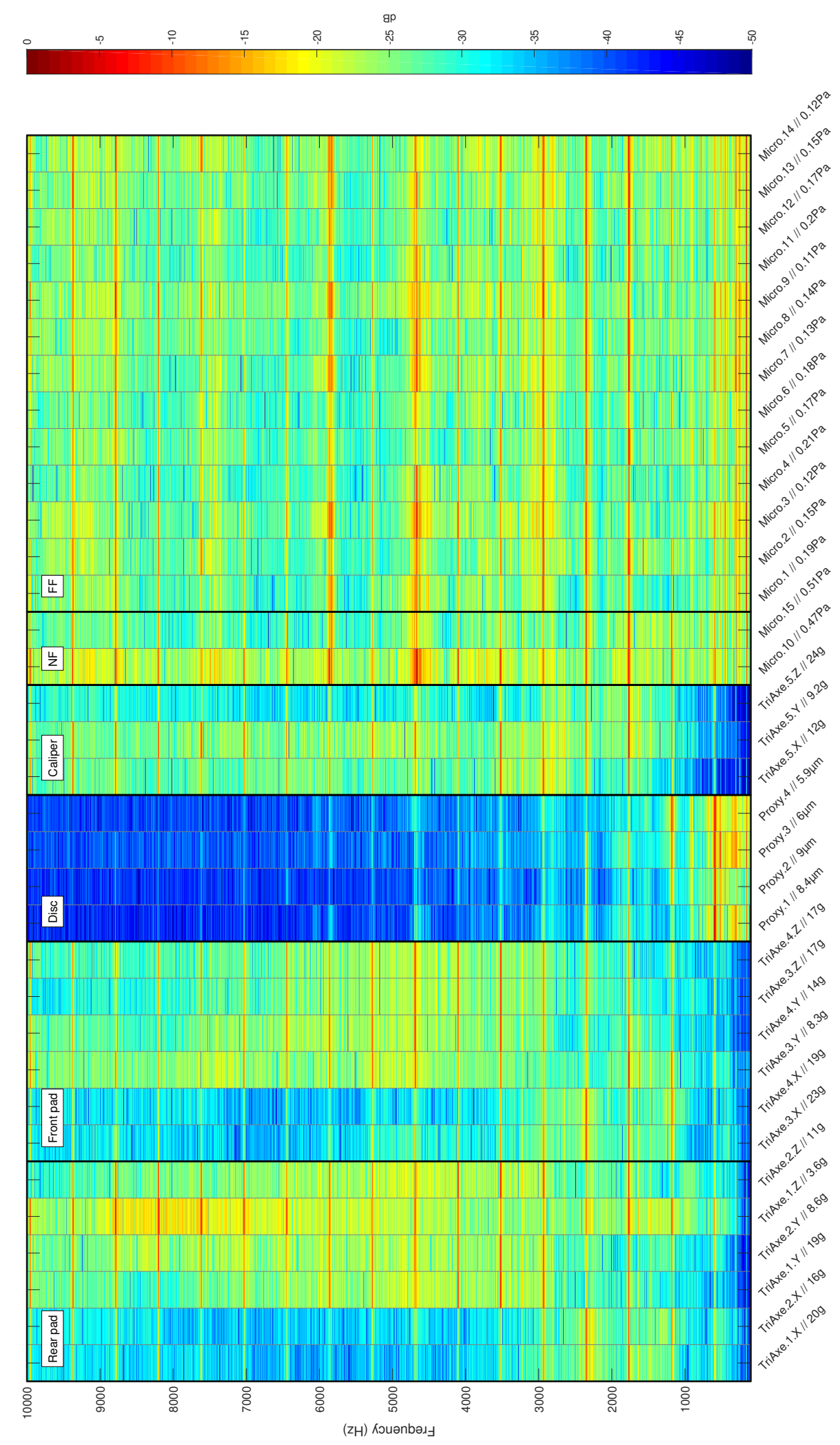

Figure 11: Normalized FFT for $t=[10 ; 11] s$

rapidly. Then a stabilization with small fluctuations of the signal is observed. So it is observed that squeal occurs as soon as the disc and the pads are in contact and is still present during the braking test. Brake squeal causes significant vibrations of the pads and the caliper in the three directions. 


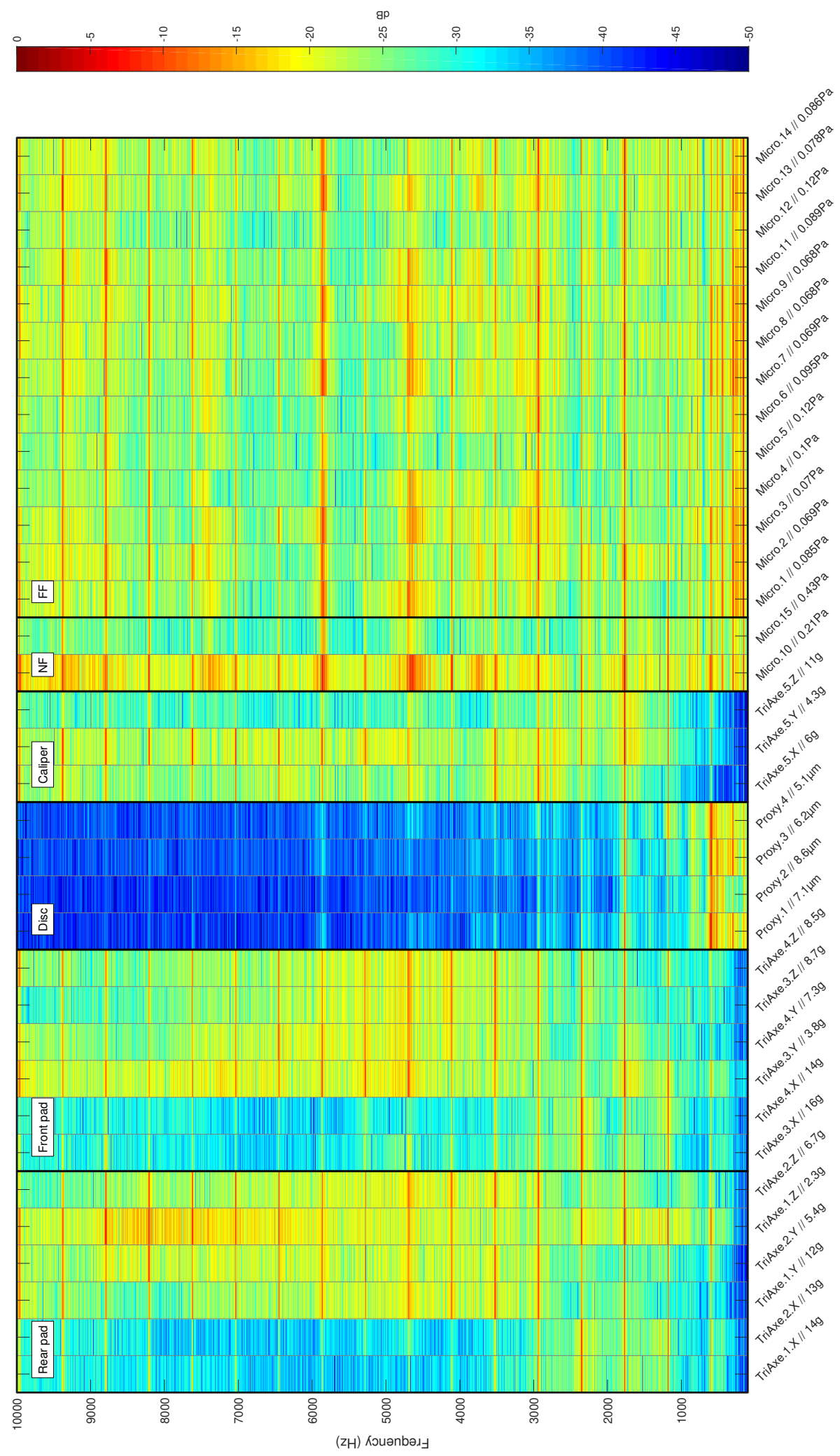

Figure 12: Normalized FFT for $t=[15 ; 16] s$

Then, sounds in near-field and in far-field also increase at $t=4 s$ with stabilization of the noise level during the braking test.

Considering more specifically the normal displacements of the disc, a non-negligible evolution of the static sliding 


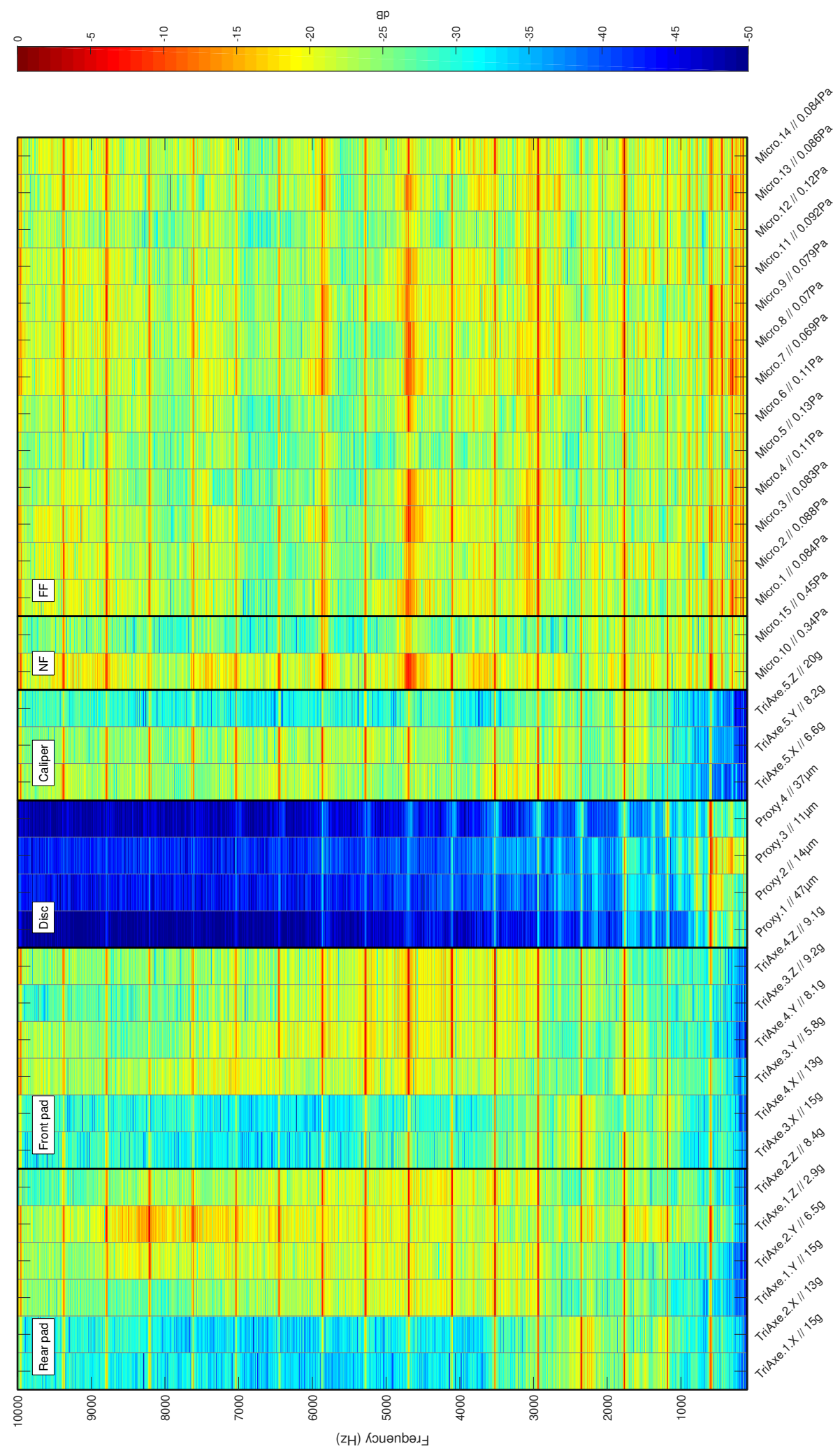

Figure 13: Normalized FFT for $t=[19 ; 20] s$

equilibrium (i.e. position of the rotating disc) is observed between $t=[2 ; 5] s$. This corresponds to the positioning 325 of the brake system and more specifically the disc and the two pads via the caliper under the effect of the pressure force during braking. As shown in Figure 8(a) the periodic rotation of the disc due to the misalignment between 
the disc/shaft and the two pads is visible during all the test. Thus the detection of the occurrence of squeal via the proximitor sensors is thus more difficult to see on the time plot because of the periodic rotation of the disc. The latter is however visible during a braking test: it is characterized as a vibration of secondary level with respect to the displacement due to the rotation of the disk, as illustrated in Figure 8(b) (see also Figure 8(a) for $t=[4 ; 6] s$ or $t=[18 ; 20] s$ for example). Moreover the most important vibrations on the disc are observed on the proximitor sensors Proxy.1 and Proxy.4 that correspond to the two sensors closest to the contact zone between pads and disc. This is that the secondary vibration of the disc is due to the squeal phenomenon already observed on the pads and disc. It has also been verified that the shaft vibration is not significant during the braking test. Only a weak deflection of the shaft was detected when contacting the disc and pads without noticeable impact on the results. Moreover, the effects of disc thickness variation (i.e. imperfection of surface condition) are negligible and not observed. The repeatability of the initialization of contacts and the repeatability of the evolution of the static sliding equilibrium of the braking system has been particularly verified. It is observed that the small periodic rotation of the disc (previously observed in Figures 8) does not cause large fluctuations of the normal load or the motor torque. Even if the periodicity of the disc can be visible, it does not drastically affect the operational conditions and the squeal phenomenon during the braking process.

Finally Figure 10 shows the estimation of the instantaneous friction coefficient for all the test. Even if it is calculated over all the time test it can be noted that this instantaneous friction coefficient is only valid over the braking time when the instantaneous torque was greater than 90 percent of the initial test control level for $t=[0 ; 2] s$ as suggested by [40. In the following it is assumed that the contact condition of the entire surface of the pad on the disc is valid. It can be noted that this assumption may be a somewhat false approximation due to the fact that the contact zones are dominated by the surface asperities. As previously explained by some researchers [33, 41, 42, 43, 44, 45, 46, 47, contact stiffness and friction at the interface introduce strong nonlinear phenomena and the true contact area between two elastic solids with rough surfaces is not everywhere in the apparent contact area. It is mainly governed by a distribution of asperity contact spots. After some braking tests it is also demonstrated that a worn discontinuous and heterogeneous area generally appears with the marks of sliding direction 33. However the proposed assumption done in the present study for the estimation of the friction coefficient allows a first approximation of the evolution of the instantaneous friction coefficient since we do not have sufficient information on the real area of contact and this investigation is outside the scope of the present study. This assumption makes it possible to use the approximated formulation given in Equation 1 to calculate the instantaneous friction coefficient. In the present case this corresponds to a usable information in the time interval $[3.85 ; 20] s$ and results before braking are not valid (i.e. the instantaneous friction coefficient should not be taken into account in the analysis).

$$
\mu(t)=\frac{C(t)-C_{\text {init }}}{n R S P(t)}
$$

$C(t)$ defines the instantaneous torque during brake application. $C_{\text {init }}$ corresponds to the mean of the initial torque before braking. $n$ is the number of contact surfaces (i.e. $n=2$ ). $R$ and $S$ are respectively area of the surface contact between one pad and the disc and the radius of the pad center. $P(t)$ defines the axial pressure applied on each pad during brake application. The value of the instantaneous friction coefficient after $t=7 \mathrm{~s}$ when both the instantaneous torque and pressure are stabilized allows to visualize the evolution of the apparent friction coefficient during the controlled braking test. It can be noted that the instantaneous friction coefficient remains constant during the brake application with $\mu=[0.5 ; 0.52]$.

\subsection{Frequency domain analysis}

The frequency results are calculated by converting into the frequency domain the previous time domain data via Discret Fourier Transform for a specific time interval. Three time intervals have been chosen in order to illustrate the repeatability of the squeal frequency signature:

- $t=[10 ; 11] s$ : beginning of the stabilized squeal event test with a constant rotational speed of 200rpm after the speed control via the motor;

- $t=[15 ; 16] s:$ middle of the stabilized squeal event test;

- $t=[19 ; 20] s$ : end of the stabilized squeal event test.

Figures 11 , 12 and 13 give the normalized FFT for the three time intervals. Each measurement is normalized independently in order to facilitate the comparison of vibration signatures between each structural component (pads, caliper and disc). This also allows a better comparison between the friction-induced vibrations and noise during a 
squeal event. The red color therefore corresponds to the maximum vibration signal observed on each specific sensor without correlation between sensors. The maximum value for each sensor is also given in the legend of the figure for more clarity on the actual levels. The symbols NF and FF mean "Near-Field" and "Far-Field" as previously indicated in Table 1. Comparing Figures 11,12 and 13 , it is observed that the identified squeal frequencies are similar for the three time intervals for a given sensor. This indicates that, for a frequency content point of view, the squeal event is globally identical throughout the test even if some fluctuation of the vibration amplitudes or squeal noise are present during the braking test. In other words, there could be an evolution of the squeal level but the vibratory signature remains identical during all the braking test.

The simultaneous presence of frequencies are detected at $440 \mathrm{~Hz}, 590 \mathrm{~Hz} \times n$ (for $n=1, \ldots, 15$ ), 770 $\mathrm{Hz}, 870 \mathrm{~Hz}$ and $2050 \mathrm{~Hz}$. Among these frequencies, the most representative and significant frequencies are located at $590 \mathrm{~Hz} \times n$ (for $n=1, \ldots, 10), 770 \mathrm{~Hz}$ and $870 \mathrm{~Hz}$. It can be noted that the three frequencies $590 \mathrm{~Hz}, 770 \mathrm{~Hz}$ and $2050 \mathrm{~Hz}$ are very close to the identified natural frequencies of the no-rotational coupled system (see Section 3.2). Frequency $870 H z$ could also be linked to frequencies $590 \mathrm{~Hz}$ and $2050 \mathrm{~Hz}\left(f_{2}=-2 f_{1}+f_{3}\right.$ with $f_{1}=590 \mathrm{~Hz}, f_{2}=870 \mathrm{~Hz}$ and $\left.f_{3}=2050 \mathrm{~Hz}\right)$. In conclusion the phenomenon of friction-induced vibration and the squeal noise appear at low/middle frequencies in the $[0 ; 10000] H z$ range with a finite number of frequency peaks. The most repeatable frequency contributions are composed of fundamental frequencies $(590 \mathrm{~Hz}, 770 \mathrm{~Hz}$ and $2050 \mathrm{~Hz})$, harmonic components $(590 \mathrm{~Hz} \times n$ for $n=2, \ldots, 15)$ and potentially harmonic combinations $(870 \mathrm{~Hz})$.

Moreover it is observed that all the vibration frequencies that have been obtained with the triaxial accelerometers and proximitor sensors coincide with the signal frequencies that have been observed with microphones measurements in far-field and near-field. So it can be concluded that the squeal event is the result from friction-induced vibrations of the disc, pads and caliper. For the reader comprehension, it can also be noted that vibration frequencies for the disc are more visible at low frequencies because of the sensors used. Indeed, proximity sensors measure displacements while the other vibration sensors measure accelerations (for the pads and caliper) and so an attenuation of the square of the pulsation affects this signal with respect to the others one.

Considering more specifically the vibration of the two pads, it is shown that many vibration frequencies (in term of intensity and level comparison between them) are similar even if some differences are visible between the normal and planar vibrations (in the x-direction and in the $\mathrm{y}$-z-directions) or from one pad to another.

Looking more closely at the measurements on the microphones Micro.10 and Micro.15 on near field, it appears that the acoustic field via the intensity of the frequency peaks acoustic field is not exactly the same. As a reminder, Micro.10 and Micro.15 are located in front of the right pad and next to it, respectively. Frequencies peaks appear to be a bit lower on Micro.15: the higher peaks that can be observed on Micro.15 are situated around $2 k H z$, which may be explained by the fact that it corresponds to a wavelength $\lambda \approx 0.17 \mathrm{~m}$ (Micro.15 is approximately located at $0.1 \mathrm{~m}$ of the right pad). These results on Micro.10 and Micro.15, and more specifically the intensity of the acoustic field, have to be considered with caution since these two microphones are located outside the acoustic cavity. So they are likely to be sensitive to reflection of the experimental environment, even if the global identified frequency signature of squeal noise is in perfect accordance with the others measurements.

It is also interesting to undertake the correlation between the vibrational frequency peaks that can be measured on the triaxial accelerometers and the proximity sensors and the identified frequencies of the acoustic field that can be measured via the microphones in near and far fields. It is observed that the identified frequencies are identical. However high frequency peaks are not necessarily identical between vibration measurements and acoustic measurements (see

400 for example results at $2340 \mathrm{~Hz}$ or $2924 \mathrm{~Hz}$ ). These interesting observations can be explained by the fact that some vibrational modes radiate more than others; they are therefore more involved in squeal noise. These results demonstrate the interest of having the possibility to measure acoustic fields in order to better understand the squeal phenomena.

Finally it can be noted that these three time intervals correspond to moments for which the application brake and the rotational speed are stabilized. A detailed analysis of the identified squeal frequencies during the pressure rise,

405 for $t=[4 ; 6]$, is not provided for the sake of brevity. Indeed the frequencies identified in the signature of the squeal for $t=[4 ; 6]$ are globally identical to those previously stated for $t=[10 ; 11] s, t=[15 ; 16] s$ or $t=[19 ; 20] s$. The only notable fact is that the predominant structural vibration that has been previously shown on the proximity sensors for $t=[4 ; 6]$ (see Figure 8(a)) corresponds to oscillations at the fundamental frequency $590 \mathrm{~Hz}$.

\subsection{Sound pressure spatial analysis}

In this section, we focus on the sound pressure radiated by the brake system during self-excited vibrations. The sound pressure radiated is calculated by considering the thirteen microphones, denoted by the associated microphone number in Figure 14

Next a linear interpolation between each measurement point is performed in order to complete the $5 \times 5$ measurement grid. The positions of the interpolated points in this manner are indicated by gray boxes in Figure 14 . So each face 


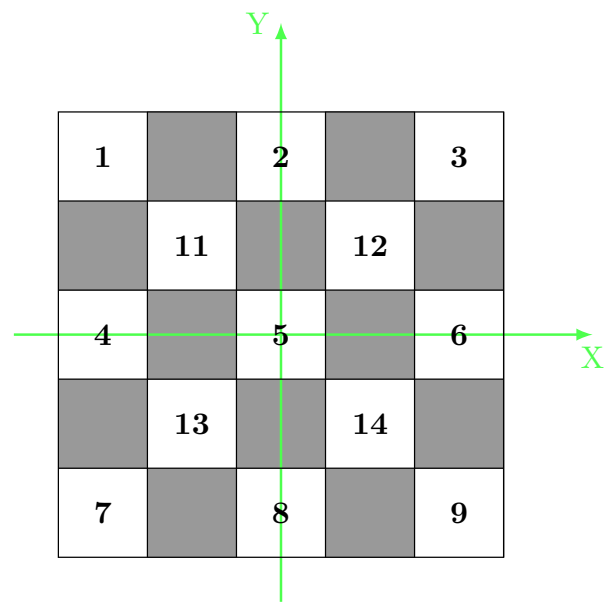

Figure 14: Definition of the $5 \times 5$ grid for the reconstruction of the radiated fields

of the complete $5 \times 5$ grid has a constant color determined by the noise level of the initial thirteen microphones. No supplementary interpolation of the true color value on one face is performed. For example interpolating the true color value across each face is avoided in order to clearly visualize the true measured or interpolated squeal noise.

Figures 15, 16 and 17 show noise emissions at some predominant selected frequencies given in Section 4.3 between $[500 ; 9000] \mathrm{Hz}$ by considering the acoustic intensity radiated in decibels. These acoustic responses are investigated on the far-field for the three time intervals $t=[10 ; 11] s, t=[15 ; 16] s$ and $t=[19 ; 20] s$. It can be noted that the given radiated fields are calculated by selecting the highest frequency peak in the frequency range centered at the initially identified frequencies plus or minus $2.5 \%$. As a reminder the initially identified frequencies are $590 \mathrm{~Hz} \times n$ (with $n=1, \ldots, 15$ ), $770 \mathrm{~Hz}, 870 \mathrm{~Hz}$ and $2050 \mathrm{~Hz}$. For the reader comprehension, the frequency ranges are indicated on the left side in Figures 15, 16 and 17. The identified highest frequency peak for each case and for each frequency range of interest is indicated below each subfigure.

Fist of all, it can be observed that the acoustic intensity displayed for a given frequency is very similar for the three time intervals $t=[10 ; 11] s, t=[15 ; 16] s$ and $t=[19 ; 20] \mathrm{s}$, except for one frequency at $2339 \mathrm{~Hz}$. Then the acoustic intensity and the propagation pattern are very different for each frequency. The acoustic levels at $1754 \mathrm{~Hz}$ and $2924 \mathrm{~Hz}$ are significantly higher than the others. Conversely the lowest noise level are constantly observed at $769 \mathrm{~Hz},[874-879] \mathrm{Hz}, 5229 \mathrm{~Hz},[6430-6435 \mathrm{~Hz}]$ and $7015 \mathrm{~Hz}$.

Because of the number of micro used, it is obvious that from a certain frequency, it is quite difficult to determine a clear pattern of the actual acoustic radiation in far field. However, the results shown here on an antenna with 13 microphones are clearly sufficient and convincing for the present study and some future studies for analyzing the acoustic field of squeal noise. To our knowledge, the realization of acoustic measurements with as many measurement points, while keeping vibratory measurements in large numbers for each structural elements such as the disc, the two pads and the caliper, has never been realized before in the context of brake squeal studies.

\section{Repeatability of the squeal event}

As previously explained, the design of the laboratory experimental bench FIVE@ECL has been designed in order to obtain reliable data during experiments of squeal noise. This implies that we have to validate not only the repeatability of the braking test and squeal event for a specific brake system but also to conduct reproducibility of the squeal conditions for two different specimens of the brake system. In the present study the validation of the repeatability of the squeal event will be performed by considering the three following cases:

- Case 1 - the reference test with the initial brake system named "System A". This test has been described in the previous Section 4.

- Cases $2 \mathrm{a}$ and $2 \mathrm{~b}$ - the same brake system "System A" with two new braking tests on the same conditions . The main objective is to validate the repeatability of the squeal event for the experimental bench FIVE@ECL.

- Case 3 - new braking test for a new brake system named "System B" on the same design configuration: two new specimens for the stainless steel disc of the same dimension and the Shimano brake pads F03C are used. The main objective is to validate the reproducibility of the squeal conditions for two different brake systems of the same design. 


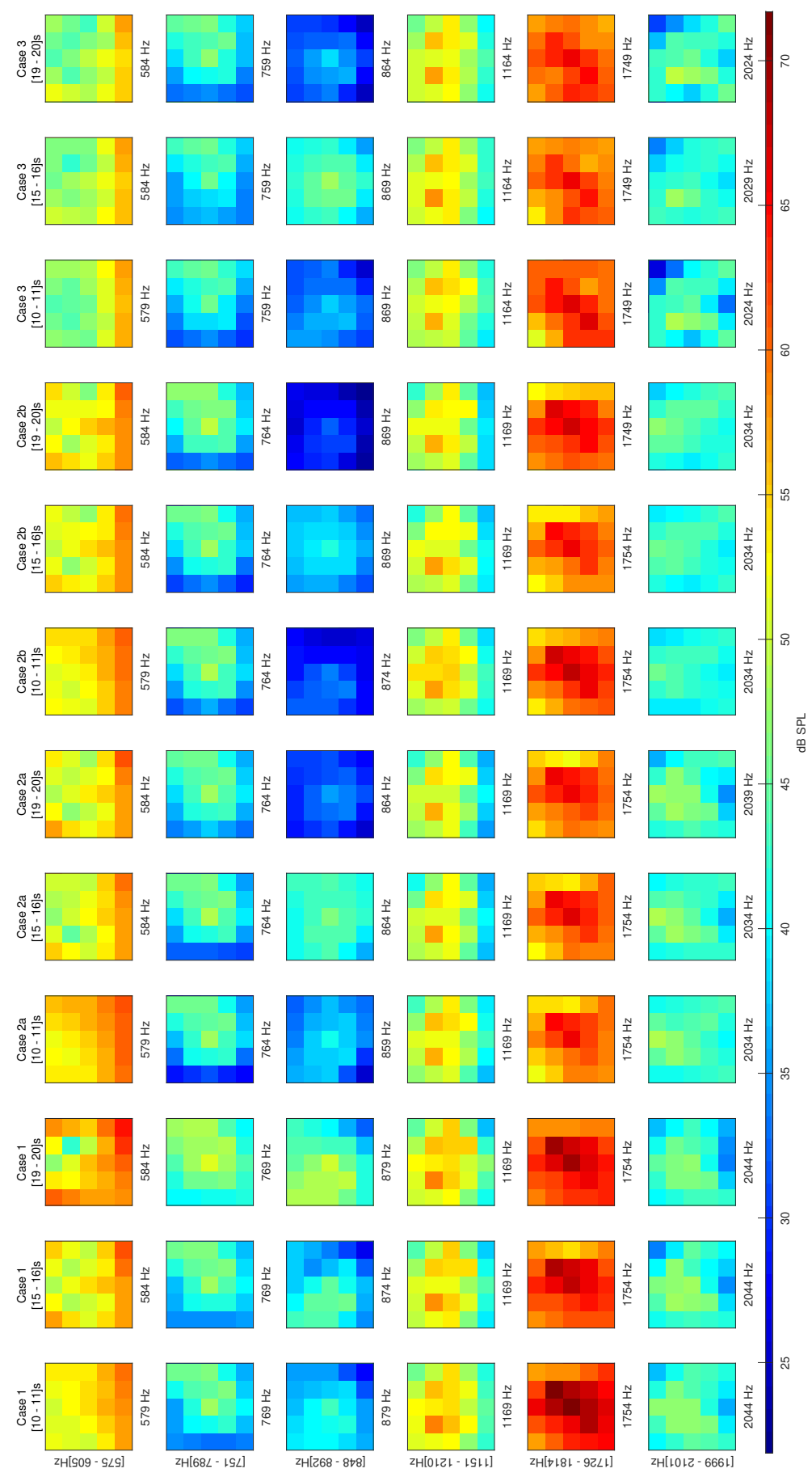

Figure 15: Radiated acoustic profiles in far field (frequency band $=[500 ; 2200] \mathrm{Hz}$ )

Each test has been performed for nearly the same operational parameters. Table 3 summarizes these different cases.

\subsection{Cases 2 versus Case 1 - repeatability of the squeal event for a given brake system}

Figures 18 and 19 give the normalized FFT for $t=[10 ; 11] s$ for the same brake system with two new braking tests, respectively Case $2 \mathrm{a}$ and Case $2 \mathrm{~b}$. Comparing this results with results of the reference case (see Figure 11 for example), it is obvious that the frequency signature is almost identical between Cases $1,2 \mathrm{a}$ and $2 \mathrm{~b}$. Results on the previously chosen time intervals $t=[15 ; 16] s$ and $t=[19 ; 20] s$ for the reference Case 1 are not provided in this section for the sake of brevity: comparisons of the results at these two instants of time would give results quite similar to those already observed. Comparison of the sound pressure radiated between Cases 1, 2a and 2b can be seen on Figures 15 . 


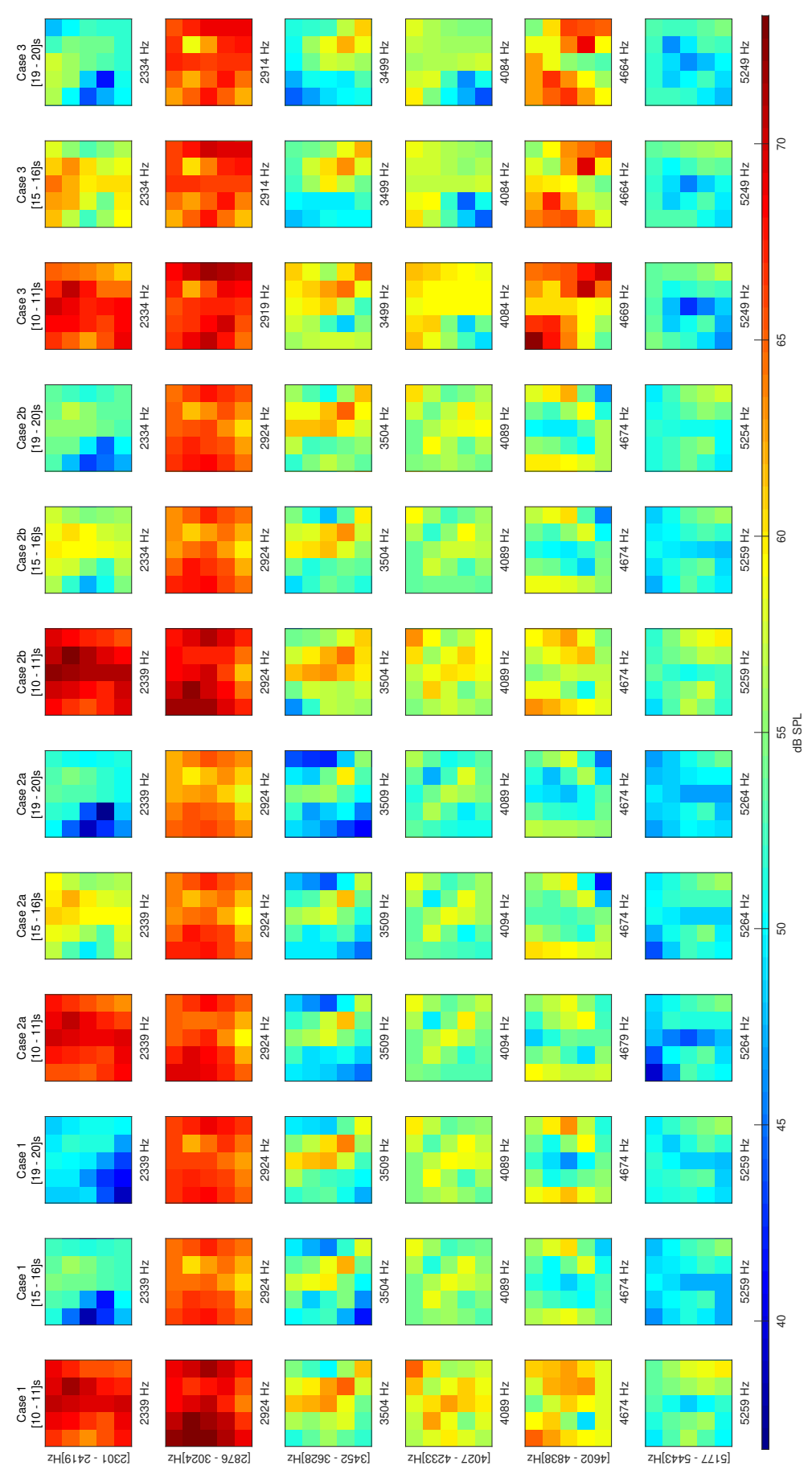

Figure 16: Radiated acoustic profiles in far field (frequency band $=[2200 ; 5500] \mathrm{Hz}$ )

16 and 17. For each frequency, the similarities of the radiated field profiles and the associated acoustic levels between ${ }_{460}$ Cases $1,2 \mathrm{a}$ and $2 \mathrm{~b}$ are unequivocal.

Moreover the evolution and decreasing of the acoustic intensity displayed at $2339 \mathrm{~Hz}$ for the three time intervals $t=[10 ; 11] s, t=[15 ; 16] s$ and $t=[19 ; 20] s$, is again observable with the same proportions of evolutions.

Finally the instantaneous friction coefficient over the braking time for both Cases 2 are given in Figure 10. It clearly appears that Cases 1 and 2 are very similar: the friction coefficient remain constant during the brake application after ${ }_{465} t=7 s$.

All these results demonstrate without any ambiguity the capacity of the bench to reproduce the same squeal signatures in vibratory and acoustic measurements for successive tests carried out on the same braking system and under the same operating conditions. 

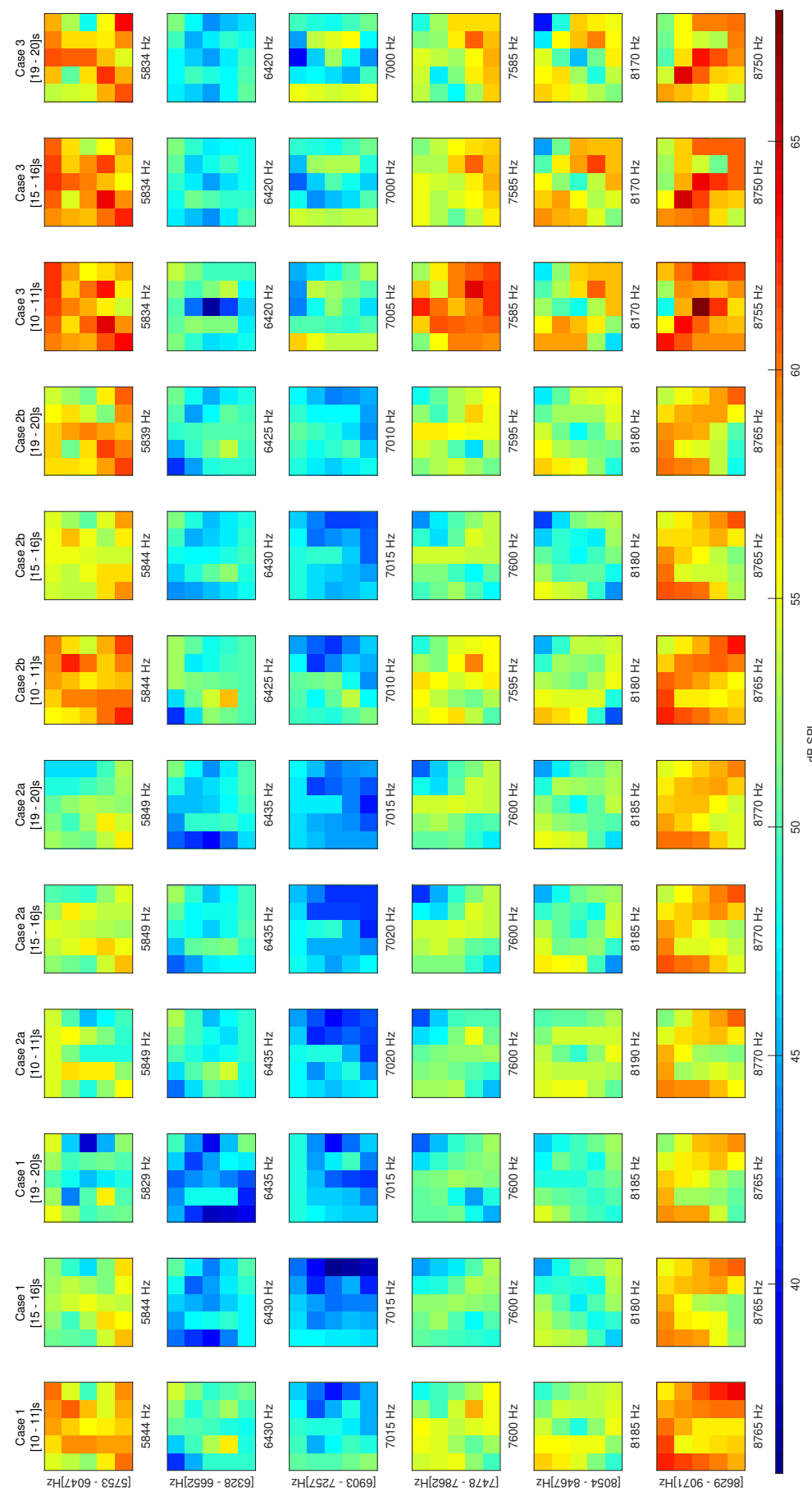

Figure 17: Radiated acoustic profiles in far field (frequency band $=[5500 ; 9100] \mathrm{Hz}$ )

\subsection{Case 3 versus Case 1 - reproducibility of the squeal event for two different brake systems of the same design}

Figure 21illustrate the evolution of squeal noise in near and far fields (to be compared with the sound measurements of the reference test given in in Figure 9) and the normal displacements of the disc (to be compared with the reference test given in Figure 8).

As previously seen for the reference test, the microphone signals are almost zero before braking. As soon as the braking is applied, the emergence of squeal sounds is characterized by a strong and rapid increase followed by a 475 stabilization of the acoustic level. The acoustic noises on the near and far fields are of the same level as for the reference case with the same fluctuations of the noise level between $[3 ; 4] P a([0.4 ; 0.8] P a$, respectively) in the near field for Micro.10 (in the far field for Micro.5, respectively). Moreover, a non-negligible evolution of the static sliding equilibrium (i.e. position of the rotating disc) is also visible again between $t=[2 ; 6] s$. For the interested reader, it 


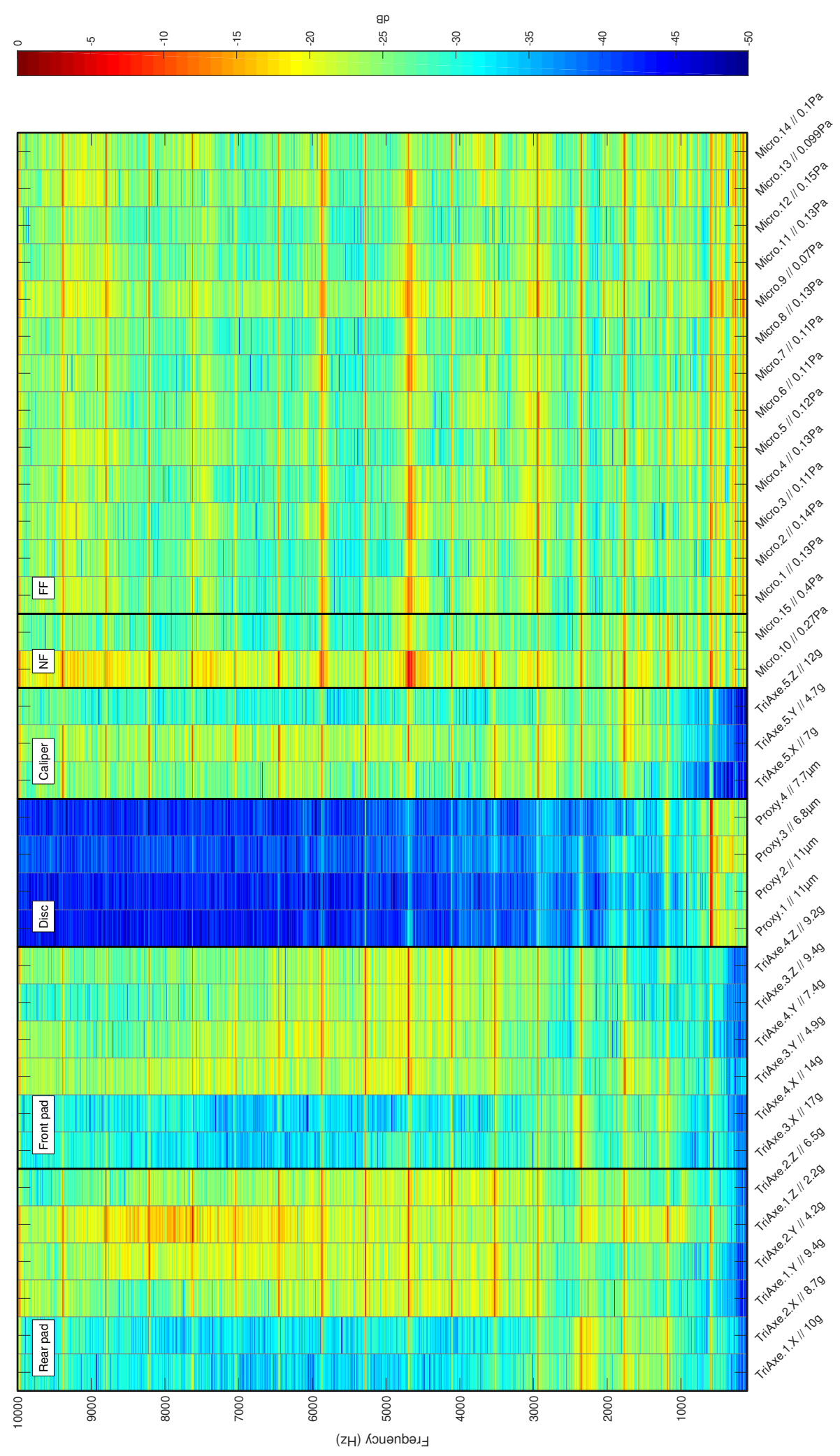

Figure 18: Normalized FFT for $t=[10 ; 11] s$ - Case 2a

can be noted that the manual pressure force is applied around $t=2 \mathrm{~s}$ with a constant application force for $t>6.5 \mathrm{~s}$. ${ }_{480}$ This explains that the emergence of the squeal noise and the evolution of the static sliding equilibrium are in advance temporally compared to the reference case. 


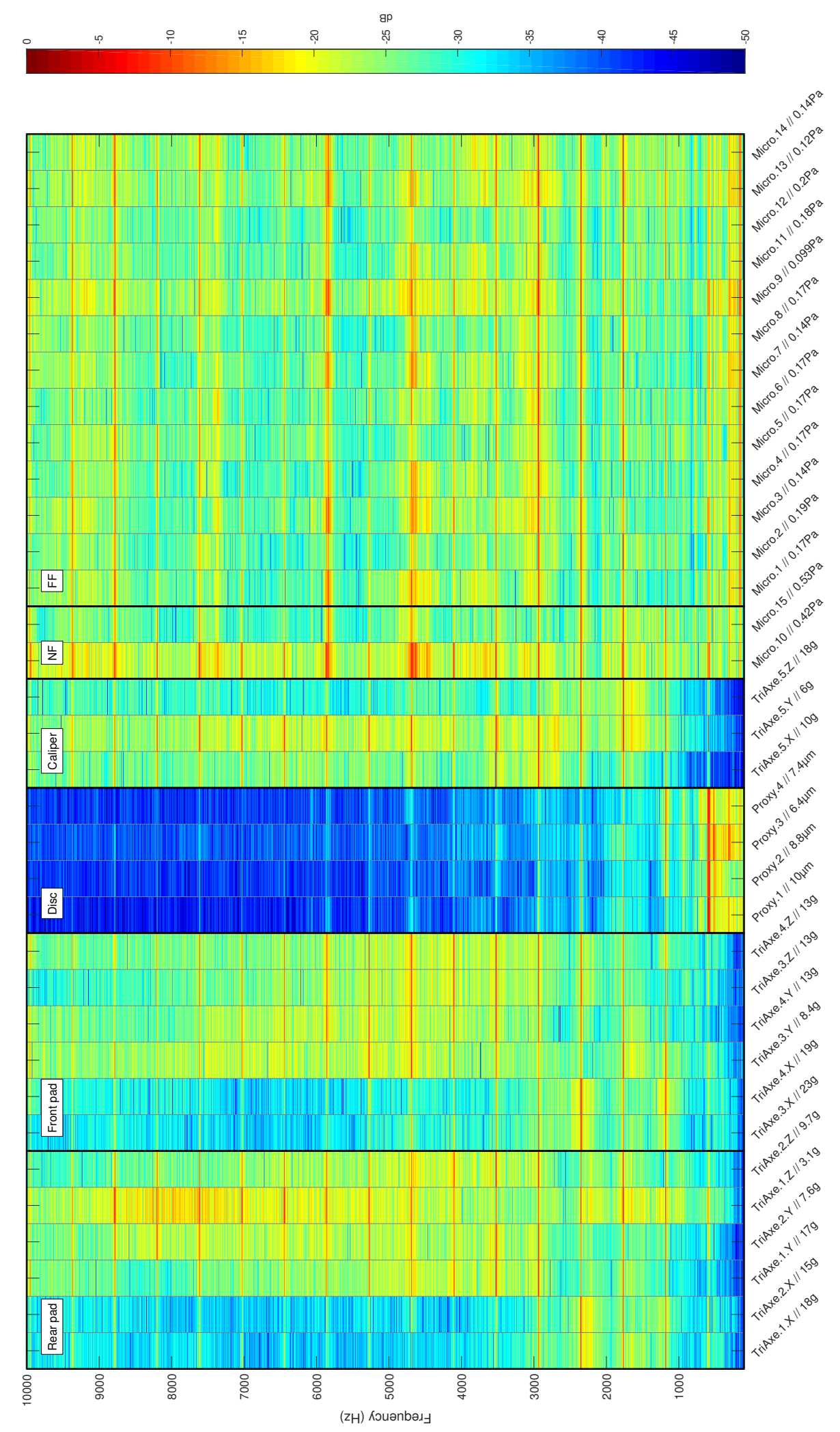

Figure 19: Normalized FFT for $t=[10 ; 11] s$ - Case 2b

As previously seen for the reference test, the squeal event is characterized by small vibrations (see Figure 21 (b) for $t=[4 ; 8] \mathrm{s}$ for example), the main oscillation being always due to the periodic rotation of the disc. This periodic motion of the disc is less significant for Case 3 than for Case 1. This reflects the fact that the the misalignment between the 


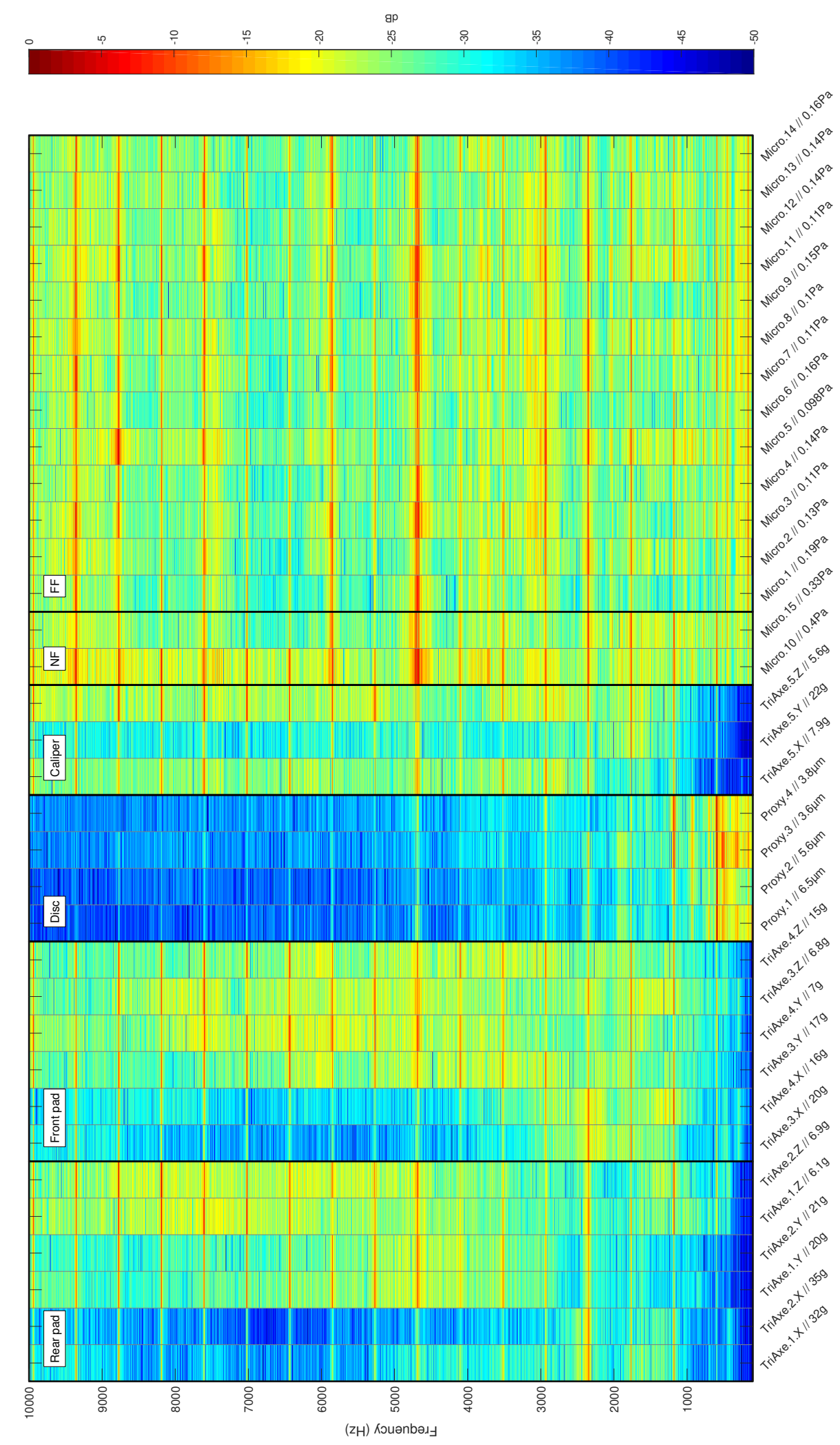

Figure 20: Normalized FFT for $t=[10 ; 11] s$ - Case 3

$485 \mathrm{disc} / \mathrm{shaft}$ and the two pads is less important for Case 3. Then the most important self-excited vibrations are again observed on the proximitor sensors Proxy.1 and Proxy.4. Finally, it can be noted that the mounting of the different sub-elements of the brake system is carried out manually. So the initial relative position (i.e. before braking) between 


\begin{tabular}{llclcrc} 
Case & Configuration disc/pads & Pressure (bar) & Rotational speed (rpm) & Phase 1 (s) & Phase 2 (s) & Phase 3 $(\mathrm{s})$ \\
\hline 1 & A & 9.2 & 203 & {$[0 ; 3.1]$} & {$[3.1 ; 6.7]$} & {$[6.7 ; 20]$} \\
2a & A & 7.8 & 203 & {$[0 ; 2.5]$} & {$[2.5 ; 6.5]$} & {$[6.5 ; 20]$} \\
2b & A & 7.2 & 202 & {$[0 ; 3]$} & {$[3 ; 6.4]$} & {$[6.4 ; 20]$} \\
3 & B & 7.7 & 203 & {$[0 ; 3]$} & {$[3 ; 6.4]$} & {$[6.4 ; 20]$}
\end{tabular}

Table 3: Characteristic of the different cases
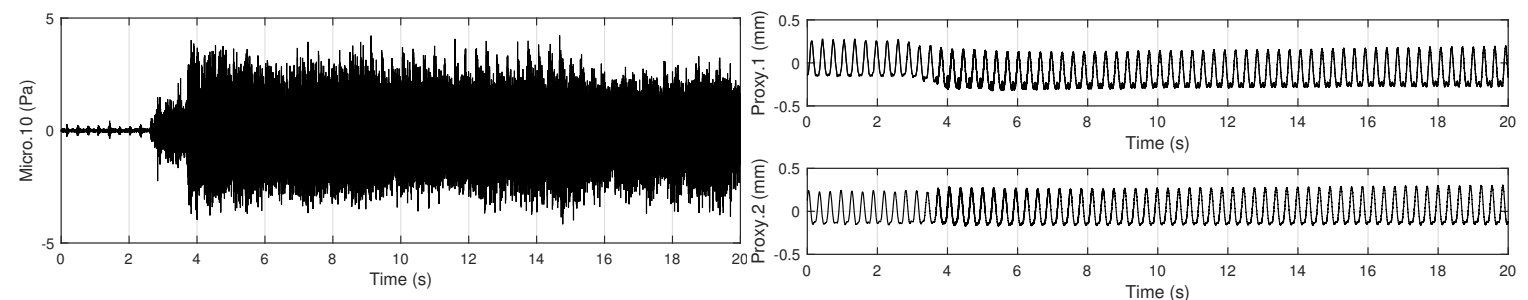

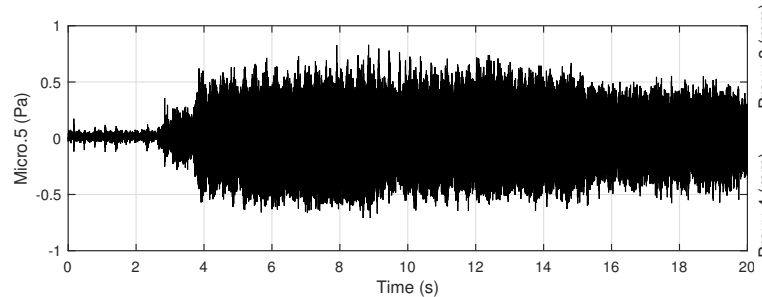

(a)

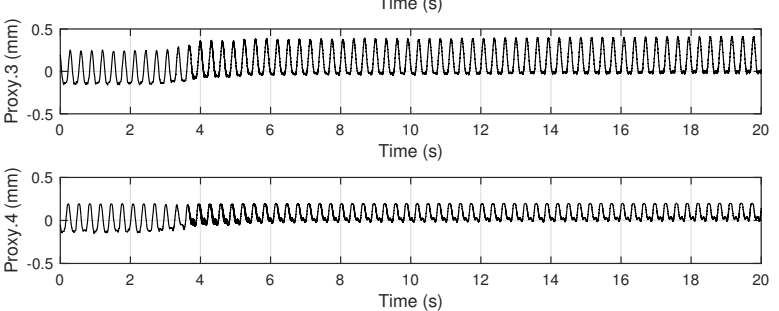

(b)

Figure 21: Time responses of (a) the squeal noise in near-field and far-field (b) the normal displacements of the disc for Case 3

the pads and disc can not be exactly the same for Cases 1 and 3. Despite this, it is observed via measurements given by the four proximitor sensors that the evolution of the static sliding equilibrium at the beginning of brake application and during all the braking test is almost identical in the two cases. This result demonstrates the capacity of the test bench to reproduce quite similarly the same kinematic conditions of the subsystems and the initialization of the contact between the two pads and the disc during braking.

Then Figures 20 give the normalized FFT for $t=[10 ; 11] s$ for Case 3. Comparing this results with results of the reference case (see Figure 11), once again it appears that the identified frequencies of the squeal event are quite similar (around $590 \mathrm{~Hz} \times n$ for $n=1, \ldots, 15,770 \mathrm{~Hz}, 870 \mathrm{~Hz}$ and $2050 \mathrm{~Hz}$ ) with the most representative and significant frequencies at $590 \mathrm{~Hz} \times n$ for $n=1, \ldots, 5$. Comparison of the frequency signature of the squeal event for each sensor between Cases 1 and 3 remains very similar. These results demonstrate the capacity of the test bench to reproduce quite similarly the same squeal event in terms of the frequency content.

Figures 15, 16 and 17 give the sound pressure radiated during Case 3. Comparing these results with the two previous cases, it can be concluded without any ambiguity that the radiated acoustic far field is identical in most cases for a given squeal frequency.

It is also very interesting to note that all the radiated fields remain practically stable in terms of acoustic intensity for the three selected time intervals except for the acoustic field identified at $2340 \mathrm{~Hz}$ that show a decreasing of the acoustic intensity with time. This result is in perfect agreement with the two previous Cases 1 and 2.

All these results demonstrate the capacity of the test bench to reproduce the radiated acoustic profiles in far field and the associated acoustic levels for two different brake systems of the same category.

Finally Figure 10 gives the instantaneous friction coefficient over the braking time for Case 3 . Its evolution is very similar with the previous Cases 1 and 2 that remain constant during the brake application even if a slight decrease in the coefficient of friction is observed, which can be explained quite easily by the fact that the pad used are not exactly the same. As previously indicated the initial evolution of the instantaneous friction coefficient during braking is different for each case due to the fact that the manual pressure force is not applied exactly at the same time for each test. This explains why the initial evolution of the friction coefficient at the begging of braking is in advance or temporally delayed compared to Cases 1 and 2 .

In conclusion all these results validate the fact that the proposed experimental bench FIVE@ECL and the associated experimental protocol are efficient in order to obtain reliable and repeatable data during experiments of squeal noise. 


\section{Conclusion}

This paper presents the design of a new experimental test bench, called Friction-Induced Vibration and noisE at Ecole Centrale de Lyon (FIVE@ECL). The main objective of this experimental test bench is to provide measurements for both friction-induced vibration of the pad, disc and caliper and squeal noise in near and far field in order to investigate the dynamic behavior of a brake system and its squeal characterization through experiments. This first contribution demonstrates that the proposed experimental protocol is mastered and able to provide reliable data during experiments of squeal noise. The reproducibility of the squeal conditions for a given set of operational parameters and for a specific brake system has been demonstrated. The repeatability of both the squeal frequency content and the radiated acoustic profiles in far field for two different brake systems of the same design has been validated too.

A complete analysis of the squeal event is investigated. Links between the self-excited vibrations of a squealing disc brake assembly and the generated squeal noise in near-field or far-field is undoubtedly observed.

Finally one of the main original and significant contribution is to provide reliable data for each component of the brake system and a complete measurement of squeal noise in far-field and near-field for the scientific community in the field of friction-induced noise and vibration. For this purpose open data of the reference braking test discussed in Section 4 is provided in 39 . The data include all the acceleration measurements on the two pads and the caliper, the normal displacements of the disc, the sound measurements in near-field and in far-field, as well as the evolution of the four operational parameters such as the pressure, the rotating speed of the disc, the motor torque and the temperature. All the results presented in Section 4 are therefore reproducible by academic researchers and industrial engineers. The objective of sharing this data sets is also to provide valuable experimental resources and to give the opportunity to researchers for conducting new analysis and testing numerical models of brake system with the proposed data.

Some non-exhaustive open issues based on the laboratory experimental bench FIVE@ECL could be considered in the future:

- study of the influence of operating conditions for a given brake system,

- a thorough investigation on links between the vibration of a squealing disc brake assembly and the squeal noise for distinct frequencies as well as complex and chaotic friction-induced dynamics,

- study of friction-induced vibration and squeal noise with respect to different brake systems by combining different types of disc, pads and caliper,

- studies of the contributions of each of the components depending on the squealing frequency of interest,

- comparisons of the frequency squeal signature of friction-induced vibrations and squeal noise between a realistic braking event and controlled braking tests,

- the improvement of correlations between experimental and numerical analysis based on linear and non-linear assessment techniques for the prediction of squeal noise,

- experimental investigation with a specific attention on the physical understanding of the appearance and generation of brake squeal.

Some other important issues such as links between squeal instability and tribological factors as well as the transient thermal evolution or transient wear state evolution during braking tests remain open questions. However the proposed bench has not been specifically designed to full understanding of brake squeal and some issues more related to tribological and thermal aspects or the multi-scale friction and contact dynamics.

\section{Acknowledgment}

The authors would like to thank Lionel Charles for his work and contribution during the manufacturing and handling of the bench, and Stéphane Lemahieu for his work and contribution during the handling and instrumentation of the bench.

The authors would like to thank the financial support provided by Ingénierie @Lyon, member of the Carnot institutes network.

J.-J. Sinou acknowledges the support of the Institut Universitaire de France. 


\section{References}

[1] A. Papinniemi, J.C.S. Lai, J. Zhao, and L. Loader. Brake squeal: a literature review. Applied Acoustics, 63(4):391-400, 2002.

[2] N.M. Kindkaid, O.M. O'Reilly, and P. Papadopoulos. Automative disc brake squeal. Journal of Sound and Vibration, 267:105-166, 2003.

[3] H. Ouyang, W. Nack, Y. Yuan, and F. Chen. Numerical analysis of automative disc brake squeal : a review. International Journal of Vehicle Noise and Vibration, 1:207-231, 2005.

[4] R.A. Ibrahim. Friction-induced vibration, chatter, squeal, and chaos part 1: mechanics of contact and friction. Am Soc Mech Eng Appl Mech Rev, 47(7):209-226, 1994.

[5] R.A. Ibrahim. Friction-induced vibration, chatter, squeal, and chaos part 2: dynamics and modeling. Am Soc Mech Eng Appl Mech Rev, 47(7):227-263, 1994.

[6] S. Oberst and J.C.S. Lai. Statistical analysis of brake squeal noise. Journal of Sound and Vibration, 330(12):2978-2994, 2011.

[7] T. Tison, A. Heussaff, F. Massa, I. Turpin, and R. F. Nunes. Improuvement in the predictivity of squeal simulations: Uncertainty and robustness. Journal of Sound and Vibration, 333(1-3):3394-3412, 2014.

[8] A. Renault, F. Massa, B. Lallemand, and T. Tison. Experimental investigations for uncertainty quantification in brake squeal analysis. Journal of Sound and Vibration, 367:37-55, 2016.

[9] J.C. Poletto, P.D. Neis, N.F. Ferreira, D. Masotti, and L.T. Matozo. An experimental analysis of the methods for brake squeal quantification. Applied Acoustics, 122:107-112, 2017.

[10] S. Panier, P. Dufrenoy, and D. Weichert. An experimental investigation of hot spots in railway disc brakes. Wear, 256(7):764-773, 2004 .

[11] X. Lorang, F. Foy-Margiocchi, Q.S. Nguyen, and P.E. Gautier. Tgv disc brake squeal. Journal of Sound and Vibration, 293(3):735 746, 2006. Proceedings of the Eigth International Workshop on Railway Noise.

[12] D. Majcherczak, P. Dufrenoy, and Y. Berthier. Tribological, thermal and mechanical coupling aspects of the dry sliding contact. Tribology International, 40(5):834-843, 2007.

[13] J.-J. Sinou, A. Loyer, O. Chiello, G. Mogenier, X. Lorang, F. Cocheteux, and S. Bellaj. A global strategy based on experiments and simulations for squeal prediction on industrial railway brakes. Journal of Sound and Vibration, 332(20):5068 - 5085, 2013.

[14] J-J. Sinou, O. Dereure, G-B. Mazet, F. Thouverez, and L. Jezequel. Friction induced vibration for an aircraft brake system. part i : Experimental approach and stability analysis. International Journal of Mechanical Sciences, 48:536-554, 2006.

[15] F. Chevillot, J-J. Sinou, N. Hardouin, and L. Jezequel. Simulations and experiments of a nonlinear aircraft braking system with physical dispersion. International Journal of Mechanical Sciences, 132(4):041010, 11 pages, 2010.

[16] N. Kado, N.Sato, C.Tadokoro, A.Skarolek, and K. Nakano. Effect of yaw angle misalignment on brake noise and brake time in a pad-on-disc-type apparatus with unidirectional compliance for pad support. Tribology International, 78:41-46, 2014.

[17] T. Butlin and J. Woodhouse. A systematic experimental study of squeal initiation. Journal of Sound and Vibration, 330(21):5077-5095, 2011.

[18] T. Butlin and J. Woodhouse. Friction-induced vibration: model development and comparison with large-scale experimental tests. Journal of Sound and Vibration, 332(21):5302-5321, 2013.

[19] K. Bonnay, V. Magnier, J.F. Brunel, P. Dufrenoy, and G. De Saxce. Influence of geometry imperfections on squeal noise linked to mode lock-in. International Journal of Solids and Structures, 75-76:99-108, 2015.

[20] F. Massi, O. Giannini, and L. Baillet. Brake squeal as dynamic instability: an experimental investigation. The Journal of the Acoustical Society of America, 120(3):1388-1398, 2006.

21] F. Massi, L. Baillet, O. Giannini, and A. Sestieri. Brake squeal: Linear and nonlinear numerical approaches. Mechanical Systems and Signal Processing, 21(6):2374 - 2393, 2007.

[22] O. Giannini and A. Sestieri. Predictive model of squeal noise occurring on a laboratory brake. Journal of Sound and Vibration, 296(7):583-601, 2006

[23] O. Giannini and F. Massi. Characterization of the high-frequency squeal on a laboratory brake setup. Journal of Sound and Vibration, $310(1): 394-408,2008$

[24] A. Akay, O. Giannini, F. Massi, and A. Sestieri. Disc brake squeal characterization through simplified test rigs. Mechanical Systems and Signal Processing, 23(8):2590 - 2607, 2009.

[25] A.R. Abu Bakar and H. Ouyang. Complex eigenvalue analysis and dynamic transient analysis in predicting disc brake squeal. International Journal Vehicule Noise and Vibration, 2:143-155, 2006.

[26] M. Kchaou, A.R. Mat Lazim, M.K. Abdul Hamid, and A.R. Abu Bakar. Experimental studies of friction-induced brake squeal: Influence of environmental sand particles in the interface brake pad-disc. Tribology International, 110:307-317, 2017.

[27] F. Massi, Y. Berthier, and L. Baillet. Contact surface topography and system dynamics of brake squeal. Wear, 265(11-12):1784-1792, 2008.

[28] M. Graf and G.-P. Ostermeyer. Instabilities in the sliding of continua with surface inertias: An initiation mechanism for brake noise. Journal of Sound and Vibration, 330(22):5269-5279, 2011.

[29] .A. Nasaruddin, M.K. Abdul Hamid, A.R. Mat Lazim, and A.R. Abu Bakar. Effects of external hard particles on brake noise of disc braking system. Applied Mechanics and Materials, 338:213-216, 2013.

[30] A.R. Mat Lazim, M. Kchaou, M.K. Abdul Hamid, and A.R. Abu Bakar. Squealing characteristics of worn brake pads due to silica sand embedment into their friction layers. Wear, 358-359:123-136, 2016.

[31] D.W. Wang, J.L. Mo, M.Q. Liu, H. Ouyang, and Z.R. Zhou. Noise performance improvements and tribological consequences of a pad-on-disc system through groove-textured disc surface. Tribology International, 102:222-236, 2016.

[32] L.Y. Barros, P.D. Neis, N.F. Ferreira, R.P. Pavlak, D. Masotti, L.T. Matozo, J. Sukumaran, P. De Baets, and M. Ando. Morphological analysis of pad-disc system during braking operations. Wear, 352-353:112-121, 2016.

[33] M. Kchaou, A.R. Mat Lazim, M.K. Abdul Hami, and A.R. Abu Bakar. Experimental studies of friction-induced brake squeal: Influence of environmental sand particles in the interface brake pad-disc. Tribology International, 110:307-317, 2017.

[34] V. Magnier, D. Naidoo Ramasami, J.F. Brunel, P. Dufrenoy, and T. Chancelier. History effect on squeal with a mesoscopic approach to friction materials. Tribology International, 115:600-607, 2017.

[35] V. Magnier, E. Roubin, J.B. Colliat, and P. Dufrénoy. Methodology of porosity modeling for friction pad: Consequence on squeal. Tribology International, 109:78-85, 2017. 
[36] D.W. Wang, J.L. Mo, Z.Y. Zhu, H. Ouyang, M.H. Zhu, and Z.R. Zhou. How do grooves on friction interface affect tribological and vibration and squeal noise performance. Tribology International, 109:192-205, 2017.

[37] O. Giannini, A. Akay, and F. Massi. Experimental analysis of brake squeal noise on a laboratory brake setup. Journal of Sound and Vibration, 292(1):1-20, 2006.

[38] N. Grabner, M. Tiedemann, U. Von Wagner, and N. Hoffmann. Nonlinearities in friction brake nvh - experimental and numerical studies. SAE Technical Paper, 2014-01-2511, 2014.

[39] J-J. Sinou, D. Lenoir, S. Besset, and F. Gillot. Dataset of vibrational and acoustic measurements for squeal analysis from the laboratory brake setup friction-induced vibration and noise at ecole centrale de lyon (fiveecl). Data in Brief (submitted), 2018.

[40] SAE International J2521. Surface vehicle recommended practice, disc and drum brake dynamometer squeal noise matrix. Technical report SAE J2521, 2006.

[41] D. Tabor. Friction-the present state of our understanding. ASME J. Lubr. Technol., 103:169-217, 1981.

[42] M. Borri-Brunetto, B. Chiaia, and M. Ciavarella. Incipient sliding of rough surfaces in contact: a multiscale numerical analysis. Computer Methods in Applied Mechanics and Engineering, 103:6053-6073, 2001.

[43] B.N.J. Persson. Relation between interfacial separation and load: Ageneral theoryof contact mechanics. Physical Review letter, 99-125502:1-4, 2007.

645 [44] H. Hetzler and K. Willner. On the influence of contact tribology on brake squeal. Tribology International, 46:237-246, 2012.

[45] A. Renault, F. Massa, B. Lallemand, and T. Tison. Experimental investigations for uncertainty quantification in brake squeal analysis. Journal of Sound and Vibration, 367:37-55, 2016.

[46] Y. Waddad, V. Magnier, P. Dufrenoy, and G. De Saxce. A multiscale method for frictionless contact mechanics of rough surfaces. Tribology International, 46:109-121, 2016.

650 [47] A. Papangelo, N. Hoffmann, and M. Ciavarella. Load-separation curves for the contact of self-affine rough surfaces. Scientific reports, pages $1-7,2017$. 